Beiträge zur physiologischen Chemie der Milch; ron

\title{
Dr. Franz Soxhlet.
}

Das Wesen des, einen Hauptbestandtheil der thierischen Milch ausmachenden Eiweisskörpers, des Caseïns, dessen genauere Kenntniss Heintz ${ }^{1}$ ) eines der dringendsten Bedürfnisse der Zoochemie nennt, ist trotz der vielfachen, diesen Eiweisskörper betreffenden Untersuchungen, welche namentlich im letaten Decennium publicirt worden sind, nicht hinlänglich aufgeklärt.

Die zuerst von Seherer ${ }^{2}$ (1841) später von Lieberkühn $n^{3}$ ) (1852) ausgesprochene Meinung, das Caseïn der Milch sei identisch mit der, durch Behandeln von Hühneroder Serumeiweiss mit Kalilauge entstandenen Eiweissverbindung, dem Kalialbuminat, und einige mit dieser Anschauung in Verbindung stehende Fragen sind es vorwiegend, welche die physiologische Chemie der Milch, als noch offen stehend bezeichnet, und deren Erörterung den Gegenstand der vorliegenden Untersuchungen bilden sollen.

\section{Das Verhalten der phosphorsauren Alkalien zum Alkalialbuminat.}

Eine Stütze jener Anschauung von der Identität des Caseïns mit Kalialbuminat, und ron wesentlichem Belang

1) H. W. Heintz, Zoochemie. Borlin 1853.

') Scherer, Ann. Chem. Pharm. 40, 19.

8) Lieberkühn, Pogg. Ann. 86, 117.

Journ. P. prakt. Chemie [2] Bd. 6. 


\section{Soxhlet: Beiträge zur physiologischen Chemie}

für die bis dahin sehr mangelhaften Erklärungsweisen der Gerinnungserscheinungen der Milch, waren die Untersuchungen Alexander Rollett's ${ }^{2}$ ) über die Eigenschaften von ,Lösungsgemengen aus Kalialbuminat und phosphorsauren Alkalisalzen". Veranlassung zu diesen Versuchen war der von Hoppe ${ }^{2}$ ) gegen die Identität dieser beiden Eiweisskörper gemachte Einwand, dass in der Milch, welche in der Mehrzahl der Fälle sauer reagire, kein Alkalialbuminat existiren könne, da die lıösungen letzterer schon beim Neutralisiren mit einer Säure gefällt würden. Diesem Einwande begegnete Rollett, indem er die Ansicht Lehmann's ${ }^{3}$, die saure Reaction der frischen Milch könne von saurem phosphorsauren Natron herrühren, unterstützte, und zeigte, dass "die Anwesenheit der phosphorsauren Alkalien in einer Kalialbuminatlösung bis zu einem gewissen Grade die Fällung des in dem Albuminat vorhandenen Eiweisskörpers durch Säuren verhindere, und man Lakmus röthende Kalialbuminatlösuugen erhält, welche erst auf weiteren Zusatz den bekannten im Säureüberschuss wieder löslichen Niederschlag absetzen."

Da es bekannt ist, dass beim Zusatz einer verdünnten Säure zu einer Kalialbuminatlösung sich ein in Wasser unlöslicher Eiweisskörper abscheidet, während sich zugleich die zugefügto Säure mit dem Kali zu einem Salz verbindet, so fragt es sich, wie die neutralen Alkaliphosphate $\left(\mathrm{K}_{2} \mathrm{H} \mathrm{PO}_{4}\right.$ und $\left.\mathrm{Na}_{2} \mathrm{HPO}_{4}\right)$, jene Zersetzung verhindern. Um diese Frage zu beantworten, hat man nach Rollett das Folgende in Betracht zu ziehen:

1) „Man setze zu einer Kalialbuminatlösung nur so viel Essigsäure, Milchsäure, dreibasische Phosphorsäure, verdünnte Chlorwasserstoff- oder Salpetersäure, als eben hinreicht, um den in Wasser unlöslichen Eiweisskörper daraus abzuscheiden.

Tropft man nun vorsichtig eine verdünnte Lösung von

1) A. Rollett, Wien. Akąd. Ber. 39, 547, 1860.

) F. Hoppe, Virchow Arch. 17, 418.

5. G. I ehmann, Handb. d. physiol. Chem. 1859. 60. u. 242. 
phosphorsaurem Kali oder Natron zu, so löst sich der ganze Niederschlag sogleich wieder auf. Die Lösung reagirt, wenn man jeden Uebersehuss der phosphorsauren Salze vermieden hat, sauer und ist durch Blutlaugensalz nicht fällbar. Ganz ungezwungen wird man den hier stattfindenden Process durch die Annahme erklären, dass ein Atom Kali oder Natron aus dem phosphorsauren Salz ausgetreten und sich mit dem Atomcomplex des fallbaren Eiweisses zu löslichem Albuminat verbunden hat, während das phosphorsaure Kali oder Natron sieh unter Aufnahme von einem Atom Wasser in ein saures Salz verwaadelt haben.

2) Man mische den oben angeführten freien Säuren so lange phosphorsaures Kali oder Natron zu, bis eine Probe vollkommen neutral reagirender Kalialbuminatlösung, durch einen Tropfen jener Mischung eben nieht mehr gefällt wird. Mit diesem sauer reagirenden Gemenge kann man nun Lösungen von Kalialbuminat in allen Verhältnissen mischen. Es entsteht weder vorübergehend noch bleibend eine Fällung, und man erhält saure, durch gelbes Blutlaugensalz nicht fällbare Kalialbuminatlösungen, kurz Lösungen, welche sich den nach 1 dargestellten vollkommen gleich verhalten.

3) Man versetze eine Lösung von Kalialbuminat mit phosphorsaurem Kali oder Natron. Ein solehes Gemenge nimmt bei vorsichtigem Säurezusatz sanre Reaktion an, ehe noch irgend eine Präcipitation erfolgt und man erhält auch hier wieder saure, durch Blntlaugensalz nicht fallbare Kalialbuminat enthaltende Lösungen. $\mathrm{Ob}$ nun in diesem Falle das Kalialbuminat durch die Säure zeriegt wird, das ausgefallte. Eiweiss sich aber sogleich wieder in dem vorhandenen phosphorsauren Salz auflöst oder ob sich zuerst aus diesem letzteren und der zugesetzten Säure, das sub 2 beschriebene, das Kalialbuminat nicht fälleude Gemenge berstellt, oder ob beide Processe neben einander hergehen, sind bis jetzt unentscheidbare Fragen. Es ist sogar denkbar, dass der Process für verschiedene Säuren ein verschiedener ist. 
Ich habe zunächst an diese Versuche angekniipft, und zwar in der Weise, dass ich sie unter Unständen wiederholte, welche einen Einblick in die Mengenverhältnisse der dabei zur Wirkung kommenden Salze und Säuren gestatteten. Daraus musste sich die Zusammensetzung des Salzgemenges ergeben, welches trotz saurer Reaction das Alkalialbuminat nicht zu fallen, im Stande ist, und sich so ein Anhalt für die Beantwortung der von Rollett aufgeworfenen Frage gewinnen lassen.

Diese quantitativen Versuche habe ich ausgefülurt mit Viertelnormallösungen von neutralem phosphorsauren Natrou ( $\mathrm{Na}_{2} \mathrm{H} \mathrm{PO}_{4}$ ), saurem phosphorsauren Kali $\left(\mathrm{K} \mathrm{H}_{2} \mathrm{PO}_{4}\right)$ und nentralem schwefelsauren Natron $\left(\mathrm{Na}_{2} \mathrm{SO}_{4}\right)$.

Diese Sulze waren durch wiederholtes Umkrystallisiren rein erhalten worden.

Als Säuren verwendete ich Sohwefelsäure, Essigsăure und Phosphorsaure gleichfalls in Viertelnormallosung. Der Titer der Schwefel- und Essigsüure wurde mit NormalNatronlauge, der der Phosphorsäure durch Gewichtsbestimmung mittelst Uran festgestellt. Die Schwefelsäure eignet sich am besten zu den Versuchen, da ihr Titer sich am sichersten festsetzen und erhalten lässt, obwohl sie Rollett unter den von ihn benutzten Säuren nicht mit anführt. Den mit der Viertel-Normal-Essigsäure erhaltenen Resultaten wurde dagegen weniger Znverlässigkeit zuerkannt, weil sich ihr Titer wegen der alkalischen Reaction ihres neutralen Alkalisalzes, weniger genau feststellen und ihrer Flüchtigkeit wegen, auch nicht constant erhalten lässt.

Die Lösungen der Salze und die Säturen wurden mit genau unter einander übereinstimmendeo Büretten abgeinessen. - Die Kalialbuminatlösung war eine $1 / 4$ procentige; sie war nach der Vorgchrift von Lieberkühn bereitet und reagirte nur sehr schwach alkalisch. Wo es darauf ankam, auch diese Spur von freiem Alkali zu beseitigen, wurde die Lösung mit so viel sehr verdünnter Schwefelsäure versetzt, bis eine ganz schwache Opalescenz eintrat; 
man konnte dann sicher sein, den erstrebten Zweck: erreicht zu haben.

Bei meinen ersten Versuchen, welche ich für den angedeuteten Zweck anstellte, verfuhr ich in der Weise, dass ich 10 oder 20 Cc. der Kalialbuminatlösung mit 5 oder $10 \mathrm{Cc}$. der Viertelnormallösung von neutralem phosphorsauren Natron versetzte, und zu diesem Gemisch unte: Umrühren tropfenweise Viertelnormal-Schw efelsäure fliessen liess, bis eine so starke. Trïbung eintrat, wie sie ein Tropfen der Viertelnormal-Schw efelsäure in $10 . \mathrm{Cc}$. der nicht mit dem Phosphat versetzten Albuminatlösung hervorbrachte. Die Fällung war hiebei eine vollständige. Bei diesen Versuchen wurden folgende Zahlen erhalten:

Kalialbuminat-
Jösung
$10 \mathrm{Co}$.
10 "
$20 "$
$20 "$

zugefügte
Phosphatlösung
5 Cc.
10 "
5 "
$10 "$

verbrauchte

Schwefelsäure

Aehnliche Versuche wurden auch unter Anwendung von Essigsäure, statt der Schwefelsäure angestellt. Die Resultate stimmten fast genau mit denen überein, welche mit der Schwefelsäure erhalten wurden, und die geringen Verschiedenheiten liessen sich recht wohl aus dem erklären, was oben über die mangelhafte Tauglichkeit der Essigsäure zu alkalimetrischen Bestimmungen gesagt worden ist. Aus den angeführten Versuchen ergiebt sich nun aber mit Bestimmtheit, dass das Albuminat erst dann so vollständig gefällt wurde, wie in $10 \mathrm{Cc}$. reiner Lüsung durch einen Tropfen Viertelnormal-Säure, wenn alles oder nahezu alles neutrale Phosphat in das saure übergeführt war. Zu zwei Versuchen wurde genau die dazu nöthige Menge Säure verbraucht, in einem Versuch etwas weniger und in einem etwas mehr. $O b$ aber diese Fällung bewirkt wurde durch freie Säure, indem die zugesetzte Säuremenge nicht blos genügte, das neutrale. Phosphat in das saure zu verwandeln, sondern auch das Alkalialbuminat zu zersetzen, oder ob das Eiweiss schon durch das saure Phosphat 
niedergeschlagen wurde, lässt sich aus den Resultatien nicht erkennen; denn die Methode ist nicht so soharf, dass sich mit Bestimmtheit sagen liesse, es sei keine freie Säure in der Flüssigkeit, welche ausgefällt wurde, enthalten gewesen. Da sich aber aus andern Versuchen ergeben hat, dass saures Alkaliphosphat Alkalialbuminat fällt, so würde auch in diesen Versuchen der Niedersehlag nicht durch die Säure, sondern schon durch das saure Phosphat erzengt worden sein; dieses hätte dem Alkalialbuminat die Basis entzogen, und ein entsprechender Theil des sauren Salzes wäre wieder in neutrales übergegangen. Diese jetzt noch offene Frage wurde durch andere vorwurfsfreie Bestimmungen bejahend entschieden.

Diese Versuche ergaben aber weiter mit Bestimmtheit, dass die zur Füllung nöthige Menge Säure in enger Beziehung steht zu der Menge des vorhandenen neutralen Alkaliphosphats, und dass es hierbei nicht auf die absolute Menge des erzeugten sauren Phosphats ankommt, sondern auf sein Verhältniss zu der Menge des noch anwesenden neutralen Phosphats. Zunächst wurde nun ermittelt, wie viel saures Phosphat nöthig sei, um eine Kalialbuminatlösung von bekannter Concentration zu fällen. Zu gleicher Zeit sollten diese Versuche darüber sichern Aufschluss geben, $o b$ in der neutrales Phosphat enthaltenden Lösung das Fiweiss wirklich durch das in ihr nach Sïurezusatz entstandene saure Phosphat niedergeschlagen wird. Fügt man aber zu einer neutrales Phosphat enthaltenden Albuminatlösung Schwefelsäure, so ist das saure Phosphat nicht das einzige Salz, welches sich bildet, sondern es entsteht daneben noch eine äquivalente Menge neutrales schwefelsaures Alkali. Da dieses möglicher Weise einen besondern Einfluss auf die Fällungserscheinungen haben könnte, so habe ich nicht eine Lösung von saurem Phosphat allein angewendet, sondern eine solehe, welche mit der äquivalenten Menge schwefelsauren Alkalis versetzt war. Ich exhielt eine solche Lösung durch Mischen eines Volumens Viertelnormallösung von saurem phospluorsanren Kali, mit dem gleichen Volumen Viertelnormallösung von 
neutralem schwefelsauren Natron. Der Titer dieser Phosphatlösung war also durch dipse Verdünnung auf die Hälfte herabgesetzt, sie war dadurch eine Achtelnormallösung geworden. Von dieser Lösung verbrauchte ich 0,8 Ce., um in 10 Ce. neutralisirter (opalescirender) Albuminatlösung eine Trübung von derselben Stärke hervorzurufen, wie durch einen Tropfen Viertelnormal-Säure. Liess ich dagegen das schwefelsaure Natron ans der Lösung des sauren Phosphats weg, und verwendete diese in der ursprünglichen Concentration, so verbrauchte ich unter sonst gleichen Verhältnissen nur $0,4 \mathrm{Cc}$, also genau halb so viel, als von der erst gebrauchten, halb so concentrirten.

Ausser der gesuchten Grösse ergiebt dieser Versuch ferner, dass das schwefelsaure Natron ohne Einfluss auf die Reaction ist, was auch daraus hervorgeht, dass, wenn man eine Kalialbuminatlösung mittelst sauren phosphorsauren Kalis fällt und dann viel oder wenig der Lösung von schwefelsaurem Natron zufügt, keine Lösung des gefallten Eiweisskörpers erfolgt. Ebenso wenig wurde der gefällte Eiweisskörper bei Gegenwart von saurem Phosphat gelöst durch Chlornatrium, essigsaures und salpetersaures Natron, auch wenn sie in grösserer Menge zugesetzt wurden, als sich beim Titriren bilden konnte. Diese Thatsache lässt darauf schliessen, dass sich die Säuren dieser Salze in den Rollett'schen Versuchen gleich der Schwefelsäure verhalten.

Fine verhältnissmässig geringe Menge des sauren Phosphats genügt, wie sich aus den vorstehenden Versuchen ergiebt, um aus einer reinen Alkalialbuminatlösung das Eiweiss zu fällen. Um aber diesen Niederschlag in einer Lösung zu erzeugen, welche auch neutrales Alkaliphosphat enthält, bedarf es einer weit grösseren Menge des sauren Phosphats, und zwar ist die hiezu nöthige Menge abhäugig von der Menge des anwesenden neutralen phosphorsauren Alkalisalzes. Um nun zu erfahren, bei welchem Verhältniss beider Salze zu einander eben die Fällung beginnt, und bei welohem das Albuminat gerade 
noch in Lösung bleibt, habe ich folgende Versuche angestellt.

Ich vermischte die Viertelnormallösungen des sauren phosphorsauren Kalis, des neutralen phosphorsauren $\mathrm{Na}$ trons und des schwefelsauren Natrons in solchen Mengen, dass die in dem erhaltenen Gemenge enthaltenen Salze in einem solchen gegenseitigen. Verhältnisse standen, wie es sich bildet, wenn man eine Viertelnormallösung des nel1tralen Phosphats mit verschiedenen aber bekannten Mengen Viertelnormal-Schwefelsäure versetzt, und prüfte nun diese Lösungen in ihrem Verhalten gegen eine Kalialbuminatlösung. Es entstand keine Trübung beim Zusatz ‘lerselben zu Kalialbuminatlösung, wenn die Lösung enthielt

\begin{tabular}{|c|c|c|c|c|c|}
\hline Neutrales & Phosphat, & Sulp & hat, & saures $\mathbf{P b}$ & hosp \\
\hline 9 & Ce. & 1 & Co. & 1 & Ce. \\
\hline 8 & , & 2 & " & 2 & $"$ \\
\hline 7 & , & 3 & , & 3 & ", \\
\hline 6 & , & 4 & " & 4 & , \\
\hline 5 & , & 5 & n & 5 & " \\
\hline 4 & . & 6 & , & 6 & , \\
\hline 3 & , & 7 & , & 7 & .. \\
\hline 2 & , & 8 & , & 8 & . \\
\hline 1 & , & 9 & .* & 9 & , \\
\hline 0, & $B$.. & 9,7 & , & 9.7 & $n$ \\
\hline
\end{tabular}

Dagegen trat eine starke 'Trübung ein, als ein Gemenge yon

$\begin{array}{ccc}\text { neutralem Phosphat } & \text { Sulphat } & \text { saurem Phosphat } \\ 0,2 \mathrm{Cc} . & 9,8 \mathrm{Cc} . & 9,8 \mathrm{Cc}\end{array}$

mit Kalialbuminat vermischt wurde, und wurde jene geringe Menge neutralen Phosphats noch um $0,1 \mathrm{Cc}$. herabgedrückt, unter gleichzeitiger entsprechender Vermehrung der beiden andern Salze, so konnte durch dieses Gemenge vollständige Fällung des Eiweisskörpers erzielt werden. Ganz ebenso verhalten sich Gemenge von saurem und neutralem phosphorsauren Alkali, ohne Beimengung von schwefelsaurem Salz.

Um die fallende Wirkung einer Lösung von saurem 
phosphorsauren Alkali aufzuheben, geniigt sonach eine relativ sehr kleine Menge von neutralem phosphorsauren Alkali, welche jedoch nicht unter ein bestimmtes Minimum sinken darf. Dieses Minimum beträgt, so weit es sich nach dem obigen Verfahren bestimmen lässt, $0,1 \mathrm{Cc}$. für 3,2 Ce. der Lösung des sauren pliosphorsauren Alkalis oder $1 \mathrm{Mol}$. $\mathrm{M}_{2} \mathrm{H} \mathrm{PO}_{4}$ auf $32 \mathrm{Mol}$. $\mathrm{M} \mathrm{Ir}_{2} \mathrm{PO}_{4}$.

A us diesem Umstande erklärt sich auch die Thatsache, dass zum Fällen einer Alkalialbuminatlösung weit mehr saures Phosphat als freie Schwefelsäure nöthig ist, während eigentlich eine äquivalente Menge des Phosphats erforderlich wäre. Denn das saure Phosphat bewirkt die Fällung, d. h. die Zersetzung des Alkalialbuminats in keiner anderen Weise als die freie Säure, es entzieht dem Albuminat die Basis. Während aber bei Anwendung ron Schwefelsäure diese blos in ein Sulphat übergeht, welches das gefällte Eiweiss nicht zu lösen vermag, verwandelt sich das saure Phosphat in neutrales Salz, welches für sich das Eiweiss aufzulösen im Stande ist. Um Alkalialbuminat aus seiner Lösung abzuscheiden, muss man also so viel saures Alkaliphosphat zusetzen, bis die Menge des neutralen Phosphats, welche sich aus der Basis des Alkalialbuminats und einem Theil des sauren Phosphats bildet, im Verhältniss zu dem sauren Phosphat weniger betrügt als $1 \mathrm{Mol}$ : $32 \mathrm{Mol}$.

Enthält eine Albuminatlösung nicht mehr saures Phosphat als das Aequivalent des gleichzeitig vorhandenen neutralen Phosphates, so lässt sich die Thatsache, dass das Albumin in Lösung bleibt, leicht erklären. Das saure Phosphat entzieht dem Albuminate die Basis, und ein entsprechender Theil des sauren Phosphats geht in das neutrale Phosphat über; dem in Freiheit gesetzten Eiweiss wird aber von dem neutrales Phosphat wieder die zu seiner Lösung nöthige Basis zugeführt, wobei sich wieder saures Phosphat bildet. Die Mengen des gebildeten sauren und neutralen Phosphats sind sich aber äquivalent, and es wird durch diesen Vorgang die Gleichgewichtslage der Moleküle nicht gestört. Allein die AJbuminat. 


\section{Soxhlet: Beitrage zur physiologischen Chemie}

lösung giebt auch dann keinen Niederschlag, wenn sie im Verhältniss zu dem in der Flüssigkeit schon vorhandenen oder in ihr erst entstehenden neutralen Phosphat, weit mehr saures enthält, als dem erläuterten durch eine Gleichung ausgodrückten Vorgange entspricht. In diesem Falle lässt sich nun zwar der chemische Process anch nicht anders deuten, wie in dem angefiihrten Beispiele, aber die Gleichung, welche den Process ausdrijckt, entspricht nicht mehr den gegebenen Mengenverhältnissen; die relativ kleinere Menge neutralen Phosphats nimmt an der Reaction $32 \mathrm{mal}$ so oft Antheil, als das saure Phosphat.

Man wird also diesen Process in die Kategorie der Gleichgewichts-, oder limitirten Reactionen einreihen können, und erledigt sich hiemit die von Rollett unter 3 aufgeworfene Frage.

Aus Vorstehendem lässt sich nun leicht auf die Zusammensetzung und Wirkungsweise jenes von Rollett unter 2 angeführten Gemenges schliessen, welehes entsteht, wenn man einer der erwähnten freien Säuren so lange neutrales phosphorsanres Alkali zusetzt, bis eino Probe Kalialbuminatlösung durch einen Tropfen jener Lösung nicht mehr gefällt wird. Dieses sauer reagirende Gemenge, welches sich in allen Verhältnissen mit Kalialbuminatlösungen mischen lässt, besteht aus dem neutralen Alkalisalz der verwendeten Säure, einer diesem äquivalenten Menge sauren phosphorsauren Alkalis und einer mit letzterem in dem bekannten Verhältnisse stehenden Menge neutralen Alkaliphosphats.

Versetzt man nümlich $9,7 \mathrm{Cc}$. Viertelnormal-Sshwefelsäure so lange mit der Viertelnormallösung des nentralen phosphorsauren Natrons, bis das Gemenge eben jene Eigenschaft hat, sich mit Kalialbuminatlösungen ohne Trübung mischen zu lassen, wozu man von dieser Lösung $10 \mathrm{Cc}$. verbrancht, so erhält man ein Gemenge, welches die gleiche Zusammensetzung hat, wie das, welches entsteht, wenn man 9,7 Cc. der Viertelnormallösung des sauren Phosphats, mit 9,7 Cc. der des scliwefolsauren 
Natrons and $0,3 \mathrm{Ce}$. der des neutralen Natronphosphats mischt; beide Salalösungen reagiren sauer und lassen sich mit Kalialbuminat, obne einen Niederschlag zu geben, mischen. Diese beiden Eigenschaften kommen jodoch auch allen andern Gemengen von schwefelsauren, essigsauren, salpetersauren oder Chloralkalien mit sauren und neutralen phosphorsauren Alkalien zu, sobald nur die Menge des neutralen Phosphats im Verhältniss zum sauren nicht unter jenes Minimum herabsinkt.

Die gewonnenen Erfahrungen lassen ferner auch leicht bestimmen, unter welchem Verhältnisse Alkalialbuminat bei Gegenwart von neutralem Natronphosphat durch Schwefelsäure, Essigsäure etc. vollständig ausgefällt wird. Auf alle Fälle darf in dern Verhältniss zu dem ontstehenden sauren Phosphat, nicht mehr neutrales Phosphat vorhanden sein als jenem Minimum entspricht. Von weiterem Einfluss ist das Verhültniss der Menge des neutralen Phosphats zu der des Alkalialbuminats. Ist nur so wenig neutrales Phosphat vorhanden, dass die Menge des aus diesem hervorgehenden sauren Phosphats, zur Zersetzung des Albuminats nicht geüugt, so muss die Fällnng durch die Säure beendet werden. Ist aber dic dazu genau hinreichende Menge neutralen Phosphats vorhanden oder mehr, so muss so viel Säure zugefügt werden, bis das noch unzersetzt bleibende neutrale Phosphat zu dem gebilcieten sauren in dem Verhältnisse steht, in welchem es nicht mehr im Stande ist, der Fällung des Albuminats entgegen zu wirken. -

Da auch Essigsäure, Chlorwasserstoff- und Salpetersäure die neutralen phosphorsauren Alkalien, in saure phosphorsaure Alkalien unter Bildung der den Säuren entsprechenden Alkalisalze verwandeln, und Lösungen saurer phosphorsaurer Alkalien mit entsprechenden Mengen der genannten Alkalisalze versetzt, - die entstandene Verdünnung in Rechnung gezogen - in ihrer Kalialbuminat-fällenden Kraft nicht verändert werden, so ist ein gleiches Verhalten dieser Säuren, wie das der Schwefelsäure, obne Bedenken anzunehmen. Ein Gleiches gilt auch 


\section{Soxhlet: Beiträge zur physiologischen Chemie}

zweifelsohne von der Milchsäure; der Nachweis hierfür konnte indess nicht geführt werden wegen der Unmöglichkeit, sich ganz reines milchsaures Alkali darzustellen; denn die milchsauren Alkalien krystallisiren nicht, und auch durch Neutralisiren einer Alkalilauge mit Milchsäure kann man diese Salze nicht rein erbalten, weil das neutrale milchsaure Kali, wie ich in anderer später zu erwähnender Weise gefunden habe, ebenso wie das essigsaure schwach alkalisch reagirt.

Nur für die Phosphorsüure trifft die Vermuthung Rollett's, dass sich bei den in Rede stehenden Processen die verschiedenen Säuren verschieden verhalten möchten, zu, wie sich aus dem chemischen Charakter der Phosphorsäure leicht ableiten lässt. Denn während sich ein Molekü] der angeführten einbasischen Säuren, zu einem Molekül sauren Phosphat und einem Molekül neutralen Alkalisalz der zugefügten Säure umsetzt:

$$
\mathrm{Na}_{2} \mathrm{HPO}+\mathrm{HNO} \mathrm{O}_{3}=\mathrm{NaH}_{2} \mathrm{PO}_{4}+\mathrm{NaNO}_{3}
$$

oder bei Anwendung von Schwefelsäure, 2 Mol. neutrales Phosphat mit 1 Mol. Schwefelsäure wieder blos 2 Mol. saures Phosphat geben, wie die Gleichung

$$
2 \mathrm{Na}_{2} \mathrm{HPO}_{4}+\mathrm{H}_{2} \mathrm{SO}_{4}=2 \mathrm{NaH}_{2} \mathrm{PO}_{4}+\mathrm{Na}_{2} \mathrm{SO}_{4}
$$

ausdrückt, so muss hingegen durch Phosphorsäure ein Mol. neutrales Phosphat in 2 Mol. saures verwandelt werden:

$$
\mathrm{Na}_{2} \mathrm{HPO}_{4}+\mathrm{H}_{3} \mathrm{PO}_{4}=2 \mathrm{Na}_{2} \mathrm{PO}_{4} \text {. }
$$

Man wird also zu einer neutrales Phosphat enthaltenden Alkalialbuminatlösung weniger Phosphorsäure als Schwefelsäure von demselben Titer setzen müssen, um das Fiweiss auszufällen; was sich auch durch Versuche bestätigt hat, die wie die früheren mit Viertelnormallösungen des Salzes und der Säure gegen 1/4 procentige Kalialbuminatlösungen ausgeführt wurden:

$\begin{array}{cccc}\text { Kalialbuminat neutrales Phosphat } & \text { Schwefelsäure } & \text { Phosphorsäure. } \\ 10 \text { Cc. } & 5 \text { Cc. } & 5 \text { Cc. } & 4,9 \text { Cc. } \\ 10 " & 10, & 9,9 " & 9,7 " \\ 20 " & 5 \% & 5,1 " & 4,9 " \\ 20 " & 10 " & 10 " & 9,8 "\end{array}$


Aus denselben Gründen wird man, um durch Zusatz einer luösung von neutralem Alkaliphosphat zu Phosphorsäure, jenes sauer reagirende, das Kalialbuminat nicht fällende Gemenge zu bekommen, mehr einer solchen Lösung verwenden müssen, als wenn man ein solches Gemenge aus einer der anderen aufgefiihrten Säuren bereiten wollte Wahrend wie friiher angegehen $10 \mathrm{Cc}$. der Viertelnormallösung von nentralem phosphorsauren Natron erforderlich war, um 9,7 Cc. der Viertelnormal-Schwefelsäure in jenes Gemenge zu verwandeln, wurde zu denselbem Zweck für eine gleiche Menge Viertelnormal-Phosphorsäure, 10,2 $\mathrm{Co}$. jener Lösung von neutralem Natronphosphat. verwendet.

Der Vorgang, welcher stattfindet, wenn man den aus Alkalialbuminat gerade ausgefällten Eiweisskörper in einer eben genügenden Menge neutralen Alkaliphosphats löst, worauf die Lösung sauer reagirt erklärt sich nach der von Rollett angegebenen Weise: das neutrale Alkaliphosphat giebt einen Theil seiner Basis an das Eiweiss ab, während es selbst in das saure Salz übergeht. Nach den gemachten Erfahrangen müssen wir jedoch hinzufügen, dass ausser der Menge neutralen Phosphats, welche gerade genügt, um das Albumin in Albuminat überzuführen, und das dann ale saures Phosphat vorhanden ist, noch so viel unzersetztes neutrales Phosphat in Lösung sein muss, als dem früher angeführten Verhältnisse zwischen neutralem und saurem Phosphat entspricht, wenn die Lösung des Eiweisses eine vollständige sein soll. Löst man dagegen nur unvollständig, so muss angenommen werden, dass sich nicht die ganze Menge des zugesetzten neutralen phosphorsauren Alkalis an jener Reaction betheiligt, sonach unzersetztes neutrales Phosphat in der Lösung bleibt, oder dass das bei der Lösung des Eiweisskörpers entstehende saure Phosphat wieder eine theilweise Fällung des Albuminats verursacbt, wobei eine Rüekbildung von neutralem phosphorsauren Alkali stattfindet.

In garı ähnlicher Weise, wie durch das neutrale Phosphat, wurde die Fäilung der Kalialbuminatlösung auch bei Eintritt saurer Reaction dureh das basische Natron- 


\section{Soxhlet: Beiträge zur physiologischen Chemie}

phosphat $\mathrm{Na}_{3} \mathrm{PO}_{4}$ verhindert. Zwischen den beiden Salzen findet nut insofern ein Unterschied statt, als das basische Phosphat noch einmal so viel Basis an der Reaction betheiligen lässt als das nentrale.

Wie die Alkaliphosphate verhält sich nun auch nach meinen Untersuchungen das neutrale Magnesiaphosphat $\mathrm{MgH} \mathrm{PO}_{4}$.

Eine mit der gesättigten Lösung dieses Salzes (im Liter Flüssigkeit 0,811 Grm. $\mathrm{MgH} \mathrm{PO}_{4}$ enthaltend) vermischte Kalialbuminatlösung kann mit einer gewissen Menge freier Säure versetzt werden, wobej saure Reaction eintritt, ohne dass sich die Flüssigkeit trübt, indem die zugesetzte Säure zur Bildung von saurem Phosphat verwendet wird; erst auf weiteren Säurezusatz erfolgt die Fällung des Kiweisskörpers. Der durch Säuren aus Kalialbuminat abgeschiedene Eiweisskörper löst sich jedoch auf Zusatz von Magnesiaphosphatlösung nicht wieder auf, da das Magnesiaalbuminat, welches hiebei entstehen müsste, nicht löslich zu sein scheint.

\section{Die Reaction der Milch und anderer thierischer Flüssigkeiten.}

Aus Allem, was bis jetzt iiber das Verhalten der Lösungsgemenge von Kalialbuminat tind phosphorgauren Alkalien gesagt wurde, geht das Eine mit Bestimmtheit hervor, dass solche sauer reagirende Lösungsgemenge, neben saurem phosphorsauren Alkali, immer noch eine bestimmte Menge neutralen Alkaliphosphats enthalten müssen. In solchen Lösungen darf letztere nicht unter ein bestimmtes Minimum herabgehen, wohl aber dieses weit überschreiten, ohne dass die saure Reaction der Lösung versehwindet.

Diese Lösungen, welche sowohl saures als neutrales phosphorsaures Alkali enthalten, reagiren nicht nur sauer, sondern wegen ihres Gehaltes an neutralem phosphorsauren Alkali, zu gleicher Zeit anch alkalisch; sie röthen blaues und bläuen rothes Lakmuspapier. 
Dieses Verhalten, welches der Beobaehtung Rollett's entgangen ist, erscheint geeignet, die Frage in bestimmtester Weise zu beantworten, ob die saure Reaction der frischen Milch von saurem phosphorsauren Natron herrühre, wie es C. (G. Lehmann ${ }^{1}$ ), oder von freier Milchsäure, wie es $\mathrm{Hoppe}^{2}$ ) will. Wenn die Ansehauung Lehmann's die richtige ist, die ja Rollett durch seine Untersuchungen zu unterstützen suchte, so muss die Milch neben der sauren auch zu gleicher Zeit dic alkalische Reaction zeigen; $d . h$. eine und dieselbe Milch muss blanes Lakmuspapier roth und rothes I Lakmuspapier blau färben. Diess ist, wiewohl es bisher nieht bekannt war, auch in Wirklichkeit der Fall. Ich habe ungefähr 40 Proben Kuhmilch auf ihre Reaction geprüft, darunter 8, welche eben erst gemolken worden waren und diese alle zeigten sowohl saure, als anch zu gleieher Zeit alkalische Reaetion.

Die Intensität beider Reactionen ist sehr wechselnd, einmal überwiegt die saure, einmal die alkalische; wenn die alkalische Reaction schwächer ist, muss man das rothe Lakmuspapier einige Secunden in die Milch eingetaucht lassen, und den herausgenommenen Streifen auf einer Porzellanplatte mit Wasser abspritzen; er zeigt dann immer eine mehr oder weniger stark violette Fürbung. Selbstverständlich ist zur Reactionsprüfung nur sehr empfindtiches, weder Säure- noch Alkaliüberschrsss enthaltendes Lakmuspapier zu verwenden. Viel deutlicher und intensiver erscheinen aber diese Reactionen, wenn man dünne mit Lakmustinetur bestrichene Gypsplatten verwendet, wie sie Liebreich ${ }^{3}$ ) zur Reactionsprufung thierischer Gewebe vorgesehlagen hat. Diese gestatten, da die trockenen Gypsplatten begierig die darauf gebrachten Flüssigkeiten einsaugen, dass eine bestimmte Menge Lakmusfarbstofl mit einer verhältnissmässig grossen Menge saurer oder

1) C. G. Lehmann a. a. 0.

7) F. Hoppe, Vircho Areb. 17, 417-451.

8) Liebreich, Ber. Berl. chem. Ges. 1, 48, 1868. 


\section{Soxhlet: Beiträge zur physiologischen Chemie}

alkalischer Flüssigkeit in Berührung kommt, was eine gesteigerte Intensität der Reaction zur Folge hat. Eine alkalische Flüssigkeit, welche Lakmuspapier nur sehr schwach violett färbt, erzeugt, besonders, wenn man kurz vorher durch Bestreichen mittelst sehr verdünnter Schwefelsäure die Gypsplatte lebhaft geröthet hat, geradezu einen blauen Fleck anf ihr, wenn man einen Tropfen der zu prüfenden Flüssigkeit auf dieselbe bringt.

Die Eigenschaft, zu gleicher Zeit blaues Lakmuspapier $z u$ röthen und rothes zu bläuen, warde schon vor längerer Zieit an manchen Harnen beobachtet und ist ron Heller amphigene, von Bamberger ${ }^{1}$ ) amphotere Reaction genannt worden.

Die unzweifelhaft amphotere Reaction der Milch macht es erklärlich, dass bis jetzt die widersprechendsten Angraben über diese Reaction gemacht wurden, und dass die Literatur über diese Frage zu einer verhältnissmässig so umfangreichen anwachsen konnte. Während die Finen die Reaction der normalen frischen Kuhmilch sauer fanden, erklärten sie die Aaderen fiur alkalisch. Schlossberger ${ }^{2}$ ) hat die älteren Angaben und Beobachtungen über diesen Gegenstand sehr sorgfältig in zwei Artikeln zusammengestellt, aus welchen ersichtlich ist, wie gross die Anzahl Derer war, welche sish mit dieser Frage beschäftigten, und dass die sehr zahlreich angestellten Versuche Dieser sich gegenseitig auffallend widersprachen.

Während Berzelius, Peligot, Lassaigne die normale Milch sauer fanden, wurden den Beobachtungen jener durch Donné's und Simon's Beobachtungen und durch die Versuche der Giessener Schule die Behauptung gegenüber gestellt, dass die Alkalescenz ganz frischer normaler Milch die Regèl sei; und man erklärte die Fälle, wo man saure Reaction fand, als durch verspätete Prüfung der Milch oder Krankheit der Thiere veranlasst. Ja, wenn man saure Reaction der frischen Milch beobachtete, so wurde

3) Bamberger, Wüuzburger med. Zeitschrift 1861, 93.

2) Schlossberger, Anr. Chem. Pharm. 87, 317 und 96, 76. 
sie als besondere Ausnahme erachtet, so dass man sie eigens beschrieb (Moleschott'), zwei Fälle saurer Kuhmilch bei Stallfütterung).

Warum die Reaction der frischen Milch bald sauer, bald alkalisch gefunden wurde, war wohl zunächst davon abhängig, welches Lakmuspapier man zufăllig oder von vorgefasster Meinung geleitet, zuerst zar Prüfung der Milch brauchte. Prüfte man mit dem blauen Papier, so fand man die Reaction sauer, konnte nun nicht anf den Gedanken kommen, dass dieselbe Flüssigkeit auch noch das rothe Papier bläue, und unterliess so die weitere Prüfung; und umgekehrt. Vielleicht übersah man auch die eine oder andere Reaction, weil das Reagenspapier nioht sehr empfindlich war. Dass aber gleichwohl die amphotere Reaction der Milch der Wahrnehmung nicht entging, wenn sie auch in ihrer Bedeutung falsch aufgefasst wurde, ergiebt sich aus einigen Angaben, nach welchen verschiedene Portionen frischer Milch, aus ein and demselben Euter, von ein und derselben Melkung verschiedene Reactionen besitzen sollten. So fand Fraas $\left.{ }^{2}\right)$ einmal die erste Maase bei der Melkung alkalisoh, die nächste sauer. Schlossborger ${ }^{3}$ ) erbob schon Bedenken gegen die Richtigkeit dieser Beobachting, da es schwer zu erklären sei, wie zur selben Zeit in demselben Euter saure und alkalische Milch rorkommen könne. Ebenso fand $\mathrm{W}, \mathrm{Zahn}^{4}$ ) in neuerer Zeit bei seinen Untersuchungen, dass „die Reaction der Milch selten schwach alkalisch, nooh seltener nentral, meistens aber schwach sauer war. Letztere Erscheinung zeigte sich immer bei den erstgemolkenen Portionen, während die letzten meistens schwach alkalisch reagirten, so dass diese drei Zustände in der Milch desselben Euters rorkommen können."

Die Annahme dieser beiden Beobachter, wonach die

1) Moleschott, Arch. f. physiol. Heilkunde 1852, 697.

2) Fraas, Virchow Arch. 7, 318.

3) Schlossberger, Ann. Chem. Pharm. 36, 76.

4) W. Zah n, Pflüger's Arch. f. Physiol. 1869, 602.

Journ. f. prakt. Cheraie [2] Bd. 6. 


\section{Soxhlet: Beiträge zur physiologischen Chemie}

in dem Euter befindliche Milch also schichtenweise entweder sauer oder alkalisch reagire, ist ein Analogon zu jenen Ammoniak-Inseln im Harn, mittelst welcher Vogel ${ }^{1}$ ) die araphotere Reaction mancher Harne erklären wollte.

Ganz undenkbar ist eine Mich von neutraler Reaction, da es weder ein neutral reagirendes Alkaliphosphat, noch ein Gemenge von phosphorsauren Alkalisalzen mit 1, 2, oder 3 Atomen Basis giebt, welches neutral reagirt. Obwohl die Angaben, man habe Milch von neutraler Reaction gefunden, oder man habe die Milch, genau" neutralisirt, sehr zahlreiche sind, so ist nichts desto weniger die Unrichtigkeit derselben anzunehmen. Ebenso können die Angaben, nach welchen durch die Selbstsäuerung eine alkalisch reagirende Milch, erst. neutral dann sauer werde, als nicht dem Thatbestand entsprechend bezeichnet werden. Will man hier nicht annehmen, dass diese Angaben nur auf Schlüssen und nicht auf Beobachtungen beruhen, insofern, als man anfangs alkalische, später saure Reaction beobachtete und dann annahm, dass zu dem Zeitpunkt, wo der Uebergang aus der alkalischen in die saure Reaction stattfand, die Mfilch nothwendig neutral reagirt haben müsse, so lassen sie sich nur unter der Annahme mit den Thatsachen in Einklang bringen, dass man eine an Alkaliphosphaten sebr arme Milch mit sehr schlecht bereitetem Lakmuspapier geprüf hat. Denn setzt man, um die saure Reaction einer Milch abzustumpfen, derselben verdünntes Alkali $\mathrm{zu}$, bis die saure Reaction verschwunden ist, so reagirt die Milch stark alkalisch; während umgekehrt, wenn man die alkalische Reaction der Mileh verschwinden machen will, man so viel Säure zusetzen muss, dass stark saure Reaction eintritt; eine so blos sauer reagirende Milch gerinnt aber schon beim Erwärmen, da die Menge des anwesenden neutralen phosphorsauren Alkalis durch den Säurezusatz, zu einur durch Lakmus nicht mehr nachweissbaren herabgedrückt wurde.

1) F. Vogel, in Vogel u. Neubauer, Analyse des Harns. 5. Auf. 231. 
Die Erkennbarkeit neutralen Alkaliphosphats neben saurem, und umgekehrt, hat, da sich die Reactionen gegenseitig doch in ihrer Intensität beeinträchtigen, natürlich ihre Grenzen, so dass sich minimale Mengen des einen, neben grossen Mengen des andern je nach der Empfindlichkeit der Lakmusreagentien nicht oder doch sehr zweifelhaft zu erkennen geben. Da man zur frischen Milch relativ ziemlich viel freie Süure zusetzen muss, um sie in jenen Zustand überzuführen, wo sie beim Erwärmen gerinnt (welche Gerinnungsweise übrigens noch besprochen werden soll), so zeugt diess von der Anwesenheit einer Menge neutralen phosphorsauren Alkalis, welche hinreicht, die alkalische Reaction der Milch zu einer unschwer erkennbaren zu machen.

Ebenso wenig wie es eine nur sauer reagirende, frische Milch giebt, kann es eine nur alkalisch reagirende geben. Denn beriucksichtigt man, wie aus den Untersuchungen von Marchand ${ }^{1}$ ), Hoppe ${ }^{2}$ ), Setschenow ${ }^{8}$ ) und Pflüger*) hervorgeht, dass die frische Milch constant Kohlensäure absorbirt enthält (nach Setschenow 5,016,74 Volumprocente), und dass dje Kohlensüure sicher wenigstens zum grössten Theil von neutralem phosphorsauren Alkali in der von Fernet angenommenen Weise absorbirt ist, . so muss in der Lösung neben saurem kohlensaurem Alkali auch saures phosphorsaures Alkali bestehen und die Milch wenigstens eine dieser Menge sauren Salzes 'entsprechende saure Reaction zeigen. Mit dieser Voraussetzung stimmen einige Erfahrungen überein, welche ich gemacht habe; so zeigte eine Lösung von neutralem phosphorsauren Natron, in die Kohlensäure eingeleitet wurde, amphotere Reaction. Ferner warden zweimal verschiedene Proben noch warmer Kuhmilch mittelst einer gewöhnlichen Luftpumpe ausgepumpt, und zwar war die Vorkehrung

1) Marchand, Dies. Journ. 44, 251.

) Hoppe, Virch. Arch. 17, 417.

8) Setschenow, Zeitschrift f. ration. Med. [3] 10, 285.

4) Pflüger, dessen Archiv der Phjeiol 1869, 166. 


\section{Soxhlet: Beiträge zur physiologisehen Chemie}

getroffen, dass das aus der Milch austretende Gas durch Barytwasser streichen musste. Das Barytwasser trübte sich dabei stark und die Proben reagirten nach dem Auspumpen etwas stärker alkalisch als vorher, aber nebenbei noch immer sauer, woraus folgt, dass sich das saure phosphorsaure Alkali mit dem kohlensauren Alkali nmgesetzt und sich etwas mehr neutrales phosphorsaures Alkali gebildet hatte.

Da eine Lösung des Magnesiaphosphats $\mathrm{MgHPO}_{4}$ mit etwas einer freien Säure versetzt, ebenfalls amphotere Reaction zeigt, so ist es wahrscheinlich, dass auch die in der Milch enthaltenen Magnesiaphosphate an der amphoteren Reaction der Milch Antheil haben; wiewohl dieser Antheil wegen des verhältnissmüssig sehr geringen Gehaltes der Milch an Magnesia nur ein sehr geringer sein kann. Selbstverständlich zeigt auch eine mit der Lösung des genannten Salzes versetzte Kalialbuminatlösung, nachdem sie durch Zufügen freier Säure angesäuert wurde, wobei noch keine Trübung eintrat, amphotere Reaction.

Die alkalische Reaction der Milch ist in bei weitem stärkerer Intensität zu beobachten, wenn man die Milch erhitzt und sie bei dieser Temperatur mit rothem Lakmuspapier prüft. Eine bei gewöhnlicher Temperatur das rothe Papier nur hellviolett färbende Milch färbt in der Hitze geprüft dasselbe dunkel violett. Lässt man dieselbe Milch wieder erkalten, so zeigt sie ihre alkalische Reaction in unveränderter Intensität, wie vor dem Erhitzen. Es ist diess eine Erscheinung, welche nichts charakteristisches für die Milch bietet, sondern allen schwach alkalischen Flüssigkeiten zukommt. Höchst verdünnte Lösung von phosphorsaurem oder kaustischem Natron zeigt ganz das. selbe Verhalten: beim Prüfen in der Hitze eine auffallend stärker alkalische Reaction. Auch violette Lakmuslösung erscheint in der Hitze $\left(80^{\circ}-90^{\circ}\right)$ merklich mehr blau, als eine mit ihr in gleich dicker Flüssigkeitsschicht verglichene kalte Portion dieser Lösung. Dass diese Thatsache nur eine Wärmewirkung, nicht etwa Folge einer Concentrationsveränderung durch Verdampfen sei, geht 
daraus hervor, dass die wieder abgekühlte alkalische Lösung dieselbe Intensität der Alkalescenz wahrnehmen lässt, wie sie sie vor dem Erhitzen zeigte.

Ebenso lässt sich die Zunahme der alkalischen Reaction in der Hitze an amphoter reagirenden Lösungsgemengen von neutralem und saurem Alkaliphosphat oder an einer Lösung von Magnesiaphosphat, welche so viel saures Salz enthält, dass beim Kochen keine Trübung entsteht, beobachten; die saure Reaction dieser Lösungen dagegen zeigt in der Wärme keine merkliche Veränderung.

Man könnte beim Alkaliphosphat vielleicht auf den Gedanken kommen, dass das neatrale Phosphat in einem solchen Gemenge sich in basisches, welches bekanntlich viel stärker alkaliseh reagirt als das neutrale, und in saures Salz zersetzt; ähnlich wie sich ja auch das neutrale Kalkphosphat $\left(\mathrm{Ca}_{2} \mathrm{HPO}_{4}\right)$ beim Kochen mit Wasser in saures und basisches Salz spaltet. Allein das Unrichtige dieser Annahme ergiebt sich schon aus den soeben mitgetheilten Thatsachen.

Ich habe die Erscheinung, dass die Milch in der Hitze stärker alkalisch reagirt, hervorgehoben, weil ich zeigen will, dass man dieselbe Thatsache an anderen thierischen Flüssigkeiten ebenfalls beobachtete, sie aber in ganz anderer Weise erklärte und aus dieser vermeintlichen Erklärnung weitere Schlüsse zog.

So beobachtet man, dass Flüssigkeiten, welche durch Kochen coagulables Eiweiss enthalten (Blutserum, hydropische Flüssigkeiten, verdünntes Hühnereiweiss) nach dem Erhitzen stärker alkalisch reagiren als vorher, und hat deshalb angenommen, dass sich vom Eiweiss beim Coaguliren dưrch Kochen Alkali abspalte.

Mit dieser Annahme erklärt sich Funke ${ }^{1}$ ) die von Du Bois-Reymond beobachtete Thatsache, dass ein frischer Muskel uach fünf Minuten langem Eintanchen in siedendes Wasser, stärker alkalisch reagire als vorher.

1) Fu n ke, Ber. d. k. sächs. Ges. d. Wissenschaften 1859, 161. 


\section{Soxhlet: Beitrige zur physiologischen Chemie}

Gerhardt ${ }^{1}$ ) gründete auf dieselbe Annahme die Theorie, Hühner- und Serumeiweisg seien als saure Alkali-Eiweissverbindungen (mit 1 Atom Basis), Caseïn als neutrale (mit 2 At. Basis) aufzufassen.

Dass auch die genannten Flüssigkeiten dasselbe Verhalten zeigen würden, wenn sie vollkommen eiweissfrei wären und nur die Salze jener thierischen Flüssigkeiten enthielten, liegt nach dem Erörterten auf der Hand. Auch wenn nachgewiesen würde, dass in solchen Flüssigkeiten durch das Kochen die Alkalescenz wirklich zunähme, so berechtigto diess doch immer noch nicht zu der Annahme einer Alkaliabspaltung vom Fiweiss; denn alle die genannten thierischen Flüssigkeiten, an denen die angebliche Alkaliabspaltung beobachtet wurde, enthalten kohlensaures Alkali; säuert man eine solche Flüssigkeit, behufs vollständiger Abscheidung des Eiweisskörpers vor dem Kochen an, so entsteht aus dem einfach kohlensauren Alkali doppelt kohlensaures Salz, welches sehr schwach alkalisch reagirt. Beim Kochen geht dieses in das viel stärker alkalisch reagirende, einfach kohlensaure Salz über, und die gekochte Flüssigkeit. kann dann thatsäehlich stärker alkalisch reagiren als vor dem Kochen. Es scheint jedoch vornehmlich das Prüfen der noch heissen Flüssigkeit jene Beobachtung zur Folge gehabt zu haben. Wenigstens konnte ich für Hühnereiweiss, das doch verhältnissmässig viel kohlensaures Alkali enthält, nach dem Erkalten der coagulirten Flüssigkeit nur eine äusserst geringe Zunahme der Alkalescenz constatiren. Ich verdünnte Hühnereiweiss sehr stark, versetzte mit Schwefelsäure, bis rothes Lakmuspapier schwach violett gefärbt wurde und erhitzte. Die noch heisse Flüssigkeit färbte das Lakmuspapier deutlich blauviolett, während die wieder erkaltete Flüssigkeit nur eine sehr wenig intensivere alkalisehe Reaction als vor dem Kochen zeigte. Das letztere ist viel zu wenig in die Augen springend und nur wahrzunehmen, wenn man ganz

1) Gerhardt, Lehrb. d. org. Chom. Uebersetzg. v. Rud. Wegner. Leipzig 1857, 4, 477. 
gleich gofärbte Iuakmuspapierstreifen, welche gleich lange Zeit in die Flüssigkeiten eingetaucht waren, neben einander anf eine weisse Porzellanplatte legt und mit einander vergleicht; während die stärkere Violettfärbung, die man beim Prüfen der noch heissen Flüssigkeit erhält, ganz auffallend ist und gar nicht übersehen werden kann. Man kann mit Gewissheit annehmen, dass die Beobachtung einer vormeintlichen Alkaliabspaltung beim Coaguliren der Fiw eisskörper in der Hitze in nichts Weiterem bestand, als in jener scheinbar stärker alkalischen Reaction, welche alle sehwach alkglischen Flüssigkeiten zeigen, enthalten sie Eiweiss oder nicht, wenn man sie bei höheren Temperaturgraden prüft.

Kühne ) führt an, dass auch Lösungen von reinem Lieberkühn'schen Albumin in nicht zu concentrirten Salzlösungen nach dem Kochen stärker alkalisch reagiren als vorher. Allerdings reagirt eine Eiweisslösung, welche man sich so herstellt, dass man eine Lieberkühn'sohe Kalialbuminatlösung durch verdünnte Säure fällt, und den frisch gefällten Niederschlag in Chlornatriumlösung wieder auflöst, nach dem Coaguliren durch Kochen schwach alkalisch. Diess ist aber auch der Fall, wenn man die Flüssigkeit mit dern eben gefällten Albumin, ohne letzteres vorher in Kochsalz zu lösen, kocht; die hierbei ebenso intensiv auftretende alkalische Reaction kann in diesem Falle um so weniger einer Alkaliabspaltung zugeschrieben werden, als hier dem Alkalialbuminat die Basis schon durch die Säure entzogen war. Die Ursache derselben ist vielmehr in dem schon angeführten Verhalten des sauren kohlensauren Alkalis beim Kochen, und in der Eigenthümlichkeit aller schwach alkalisch reagirenden Flüssigkeiten zu suchen, scheinbar stärker alkalisch zu reagiren, wenn sie in der. Wärme auf ihre Reaction geprüft werden.

Bedient man sich nämlich zur Prüfung der Reaction der Gypsplatten statt des Lakmuspapiers, so gewinnt man

1) Kühne, Lehrbuch d. physiol. Chem. 1868, 178. 


\section{Soxhlet: Beiträge zur physiologischen Ohemie}

sehr bald die Ueberzeugung, dass es überhaupt unmöglich ist, sich eine neutral reagirende Kalialbuminatlösung zu verschaffen. Die Lösungen reagiren immer alkalisch, enthalten also freies Alkali. Durch die Einwirknng dor Kohlensäure der Atnosphäre geht dieses sehr bald in kohlensaures Salz über, aus welchem beim Ausfällen des Albumins durch Säıre saures kohlensaures Salz entateht; beim Kochen wird dieses wieder in das neutrale Salz verwandelt; und diese so entstandene minimale Menge neutralen kohlensauren Salzes verursacht jene sehr schwach alkalische Reaction, deren deutliche Erkennbarkeit überdiess dadurch ermöglicht wird, dass man die Flüssigkeit in der Hitze mit Lakmusgypsplatten oder ompfindlichem Reagenzpapier prüt. Diese Fehlerquelle liesse sich zwar vermeiden, wenn man den Versuch mit dem gut ausgewaschenen Niederschlag anstellte; allein diess ist deshalb unmöglich, weil sich das gefällte Fiweiss nach längerem Auswaschen nicht mehr in Kochsalzsolution auflöst. Wäre auch dieser Versuch einer Erklärung der Zunahme der alkalischen Reaction nicht stichhaltig, so ist os sicherlich anch nicht dis von Kühne; denn wie sollte man sich, ohne den Boden der Chemie zu verlassen, die Abspaltung von Alkali in einer Lösung ron alkalifreiem Albumin in Kochsalzlösung erklären, da die Chlorwasserstoffsäure keine sauren Salze bildet, und hiebei auch keine Chlorwasserstoffsăure entweicht.

In dem Mitgetheilten findet auch die schon erwähnte, von Da Bois-Reymond beobachtete Thatsache ihre vollständigste Erklärung. $\mathrm{Du}$ Bois-Reymond ${ }^{1}$ ) fand nämlich die Reaction der Querschnitte frischer, noch leistungsfähiger, quergestreifter Muskeln amphoter, ohne jedoch als die Ursache dieser Reaction, die einen grossen Theil des Muskelsaltes ausmachenden Alkali- und Magnesiaphosphate zu betrachten. Die Erscheinung, dass ein solcher Muskel, wenn er 5 Minuten lang in siedendes Wasser getaucht wird, stärkere alkalische Reaction zeigt,

1) Du Bois-Reymond, Berl. Akud.Ber. 1859, 288. 
suchte Du Bois-Reymond zuerst durch die Vermuthang zu erklären, dass sich bei dieser Temperatur im Muskel ein Alkali, vielleicht Ammoniak entwiekelt habe, gab aber dann diese Erklärungsweise wieder auf, ohne Anderes an ihre Stelle zu setzen. Gewiss war auch bier die Veranlassung zu jener Beobachtung, dass der noch heisse Muskel auf seine Reaction geprïft wurde.

Gegen die Möglichkeit, dass die saure Reaction des todtenstarren Muskels von saurem phosphorsanren Kali herrühren könne, erhob Du Bo is-Reymond') einen scheinbar wichtigen Einwand, der jedoch, wie ich sogleich zeigen werde, gegenstandlos ist. Du Bois-Reymond machte nämlich daranf aufmerksam, dass die rothen Flecke, welche die Querschnitte todtenstarrer.Muskeln anf blauem Lakmuspapier hervorbringen, beim Trocknen des letzteren nicht versehwinden und sonach dieselben ,nicht allein wie die Herren Valenciennes und Frémy wollen, ron saurem phosphorsauren Kali herrühren; denn die, wie Herr Mitscherlich gezeigt hat, von saurem, phosphorsauren und arsensauren Kali auf blaues Lakmuspapier gemachten Flecke verschwinden beim Trocknen, weil das Salz beim Krystallisiren wieder die Süure aufnimmt, welche das Lakmus röthete" . Ich erwähne diesen Einwand, weil er ebenso gut gegen die Anschauung erhoben werden könnte, dass die saure Reaction der Mileh von saurem phosphorsauren Alkali herrühre, obwohl diess bis jetzt in directer Weise noch nicht geschah. Nur Kemmerich") betont einmal, dass die Milch dauernd Lakmus röthete, ob mit Hinblick auf das von Mitscherlioh angegebene Verhalten des sauren phosphorsauren Kalis, ist nicht ersichtlich.

Diess Angabe Mitscherlich's, wclche in vielen Lehr- und Handbüchern der physiologischen und reinen Chemie angeführt wird, kann ich jedoch in bestimmtester Weise als unrichtig bezeichnen, womit auch der Möglichkeit des erwähnten Einwandes vorgebeugt ist.

1) A. a. O.

2) Kemmerich, Pflüger's Archiv der Physiol, 1869, 405. 


\section{Soxhlet: Beiträge zur physiologischen Chemie}

Eine Lösung von saurem phosphorsauren Kali, welches dureh fünfmaliges Umkrystallisiren gereinigt war, röthete in den versehiedensten Concentrationen angewendet, das blaue Lakmuspapier dauernd; die Röthung verschwand weder nach dem Trocknen, noch nachdem die gerötheten trockenen Papierstreifen acht Tage lang aufbewahrt waren. Ebenso verhielten sich Lösungsgemenge von saurem und neutralem phosphorsauren Kali und Natron, in denen die Anwesenheit freier Säure vollkommen ausgeschlossen ist; und Lösungen von neutralem phosphorsauren Natron, welche mit Schwefelsäure bis zum Eintreten der amphoteren Reaction versetzt waren. Nie konnte ich ein Verschwinden der Röthung, wenn solche auch noch so gering war, nach dem Trocknen in der Wärme oder auch nach längerem Aufbewahren der Papierstreifen beobachten.

Es sei mir gestattet, hier noch einen Gegenstand zu berühren, der gleichfalls in Zusammenhang stebt mit der amphoteren Reaction der thierischen Flüssigkeiten, nämlich die Bestimmung des Gehalts des Harns an sogenannter freier Säure.

In vielen Füllen reagirt der menschliche Harn sauer, and es unterliegt keinem Zweifel, dass diese Reaction bedingt ist dureh den Gehalt des Harns an sauren phosphorsauren Salzen. Für den vorliegenden Gegenstand ist es

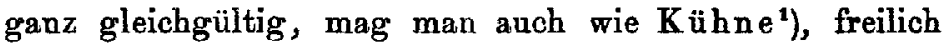
ohne allen Grund, die Frage noch als ungelöst betrachten, ob sich nicht auch noch freie Säure an der sauren Reaction des Harns betheilige. - Man hat nun den Säuregrad des Harns, die "freie Säure" des Harns zn bestimmen gesucht und vorgeschlagen, den Harn bis zum Eintritt der neutralen Reaction, mit einer Alkalilösung von bekanntem Gehalt zu versetzen. In der That sind auch derartige Bestimmnngen in grosser Anzahl ausgeführt worden. Wie geringen Werth aber dergleichen Untersuchungen haben and wie schlecht die vorgeschlagene Methode ist, ergiebt sich daraus, dass ein lösliches phosphorsaures Salz, welches

1) Kühne, Lehrb. d. physiol. Chemie 1868, 511. 
vollständig neutral rengirt, also weder die Farbe des rothen noch des blauen Lakmuspapiers verändert, gar nicht besteht. Fügt man zu einer Lösung von saurem Alkaliphosphat Natron- oder Kalilauge allmählich in kleinen Mengen hinzu, so nimmt zwar die saure Reaction ab und verschwindet endlich ganz; aber wenn eben dieser Punkt eingetreten ist, so reagirt die Flüssigkeit, auch wenn keine Spur überschüssigen Alkalis zugesetzt worden ist, schon alkalisch; lässt man aber nar so viel Lauge zufliessen, dass die Flüssigkeit eben anfängt alkalisch zu reagiren, so reagirt sie gleichwohl noch deutlich saner. Daraus ist ersichtlich, dass es in dieser Weise überhaupt unmöglich ist, den Säuregrad des Harns quantitativ zu bestimmen Man sollte nun meinen, dass ein so augenfälliger Umstand doch kaum den zahlreichen Beobachtern entgangen sein könnte. Das scheint auch in der That der Fall gewesen zu sein, wenn man auch nirgends eine directe Angabe hierüber findet. Es ergiebt sich diess aus der verschiedenen Weise, wie nach den Handbüchern die Endreaction festgestellt werden soll.

Charakteristisch für den Sachverhalt ist, wie $\mathrm{N} e \mathrm{u}$ bauer ${ }^{2}$ ) diess thut. Zunächst soll man Natronlauge zusetzen, bis das Lakmuspapier nicht mehr geröthet wird. Man prüft dann, ob die Flüssigkeit schon alkalisch reagirt, notirt sicb das Volum der verbrauchten Natronlauge und macht den Versuch mit einer neuen Harnportion noch einmal, setzt jedoch einige Tropfen weniger zu , und wird nun durch häufiges Prüfen den Sättigungspunkt ganz genau treffen". Dieger Trost, den Neubauer dem Experimentirenden giebt, man werde schon den Sättigungspunkt ganz genau treffen, den er offenbar selbst nicht getroffen hat, wenn man man nur recht hänfig prüft, der Rath, etwas Unmögliches durch den Fleiss exzwingen zu wollen, ist nicht geeignet, für das Fehlerhafte der Methode Ersatz zu bieten.

1) Nenbauer, Analyse des Harns, 5. Aufl., 167. 
28 Soxhlet: Beiträge zur physiologischen Chemie

v. Gorup-Besanez ${ }^{1}$ ) begnügt sich mit der Vorsehrift, den Harn so lange mit Natronlauge zu versetzen, bis er empfindliches blaues Lakmuspapier nicht mehr röthet, geröthetes aber noich nicht bläut; je empfindlicher aber die Reagenzpapiere sind, um so weniger wird man dieser Anforderung genügen können.

Hop $\mathrm{P}^{3}$ ) wird dagegen doch schon den Thatsachen gerecht, wenn er vorschlägt, den Harn nur mit so viel Natronlauge zu versetzen, bis Lakmuspapier durch das Gemisch gerado violett gefärbt erseheint; wenn man auch aus andern Gründen der Tauglichkeit dieser Endreaction nicht beipflichten kann. Wenn nämlich die Bestimmang der freien Säure im Harn überhaupt einen Sinn haben soll, so kann damit nur beabsichtigt sein, den Gehalt des Harns an saurem Phosphat zu ermitteln; diesen erfäbrt man aber nicht, wenn man bis zur violetten Färbung des Harns titrirt, denn dann enthält der Harn noch saures• Phosphat, und nach Ueberführung allen sauren Phosphats in das neutrale reagirt der Harn alkaliseh. Dieser Anforderung entspricht weit besser die Vorsehrift von $\mathbf{M o h r}^{3}$ ), wonach man so lange Kalilauge zu dem Harn setzen soll, bis violettes Lakmuspapier leicht gebläut wird; allein anch dann wird man der völligen Umsetzung des sauren in das neutrale Phosphat noch nicht sicher sein.

Die Unsicherheit der Endreaction bei der Bestimmung des sauren Phosphats im Harn durch Titriren mit Natronlauge hat darin ihren Grund, dass das entstehende neutrale Phosphat neben dem noch vorhandenen sauren Phosphat noch in Lösung bleibt und. so die Röthung des blauen Papiers, welche das saure Phosphat bewirkt, dureh das neutrale Phosphat verdeckt wird, und zwar um so mehr, je mehr die Menge des sauren Phosphats abnimmt. Dagegen wird man zu dem Ziele gelangen, wenn man dafür

1) v. Gorup-Besanez, Anleitg. z. zooohem. Anal., 3. Aufl. $1871,297$.

2) Hoppe-Seyler, Handb., 3. Aufl, 1870, 256.

3) Mohr, Lebrb. d. Titrirmethoden, 3. Aufl, 1870, 638. 
sorgt, dass das neutrale Phosphat sofort nach seiner Bildung als unlösliche Verbindung aus der Lösung entfernt wird, und diess könnte man erreichen, wenn man den Harn von vorn herein mit einem Neutralsalz versetzt, welches mit dem neutralen Natronphosphat einen unlöslichen Niederschlag giebt. Dazu scheint sich vor Allem das Chlorbarynm zu empfehlen, allein gegen die gewöhnliche Annahme reagirt eine Lösung von neutralem Natronphosphat nach dem Ausfällen mit Chlorbaryum sauer, woraus folgt, dass sich neben dem neutralen phosphorsauren Baryt auch eine kleine Menge sanres und basisches Phosphat bildet, sich also ein Theil des Natronphosphats mit dem Chlorbaryum in derselben Weise umsetzt, wie nit dem salpetersauren Silberoxyd die ganze Menge. Anch das Chlorcalcium eignet sich nicht zu diesem Zwecke, denn die Fliussigkeit reagirt nach dem Fällen auch sauer und sogar noch bedeutend stärker als bei Anwendung von Chlorbaryum.

Der Gegenstand muss also noch weiterer Erörterung überlassen bleiben.

\section{Die Fällung der Milch dureh Lab.}

Durch die Nichtfällbarkeit einer reinen Kalialbuminatlösung, durch Digestion mit der Schleimhaut des Kälberlabmagens, sah sich Lieberkühn ${ }^{1}$ ), - wenn er auch diesem Unterschied wegen der noch unvollkommen gekannten Wirkungsweise des Lab's nicht zu grosses Gewicht beilegen zu müssen glaubte, - dennoch veranlasst von einer bestimmten Identitätserklärung des Kalialbuminats mit Caseïn Abstand zu nehmen. Es ergab sich jedocb bald, dass auch das Caseïn nicht unmittelbar durch Lab gefällt wird, indem Simo ${ }^{2}$ ) zeigte, dass das Lab zunächst den Milchzucker der Milch in Milchsäure verwandelt, welche dann das Caseïn durch Basisentziebung fällt,

1) Lieberkühn, a. B. O.

2) Simon, Handb. d. medio. Chemie, 1, 85 


\section{Soxhlet: Beiträge zur physiologischen Chemie}

woranf sich nun auch herausstellte, dass sich unter diesen Bedingungen das Alkalialbuminat, wie das Caseïn verhielt. So konnte M. Schultze ${ }^{1}$ ) Alkalialbuminat aus der Flüssigkeit der mittleren Arterien- and Venenhaut nach Zusatz von etwas Milchzucker durch Digestion mit Kälberlab niederschlagen. $\operatorname{Panum}^{2}$ ) löste die aus Ochsenblutserum mittelst Essigsäure gefällten Eiweisskörper in phosphorsaurem oder kohlensaurem Natron, erhielt also Natronalbuminat, emulgirte diese Lösung unter Zusatz von Milchzucker mit Fett und brachte diese künstliche Milch durch Lab zum Gerinnen. Ausführliche Verauche mit nach Lieberküihn bereitetem Alkalialbuminat machte Skrzeczka ) und fand, dass Alkalialbuminat nur bei Gegenwart von Milohzucker oder besser noch bei Gegenwart von Milchzucker und Fett durch Digestion mit Kälberlab gefällt wird.

So schien denn eine Verschiedenheit zwisehen dem Verhalten des Caseïns und Alkalialbuminats gegen Lab nicht zu bestehen. Allein die Behauptung Simon's'), dass die Gerinnung einer alkalisch gemachten Milch mittelst Lab erst dann erfolge, wenn schon saure Reaction eingetreten sei, wurde durch die Beobachtungen von Selmi ${ }^{5}$ ) als unhaltbar erwiesen, dieser fand nämlich, dass das Lab die Eigenschaft habe, das Caseïn in der Wärme, auch in alkalisch reagirender Milch, ohne dass diese alkalische Reaction verschwindet, in die unlösliche Modification überzuführen, was sich dureh Säurezusatz nicht bewerkstelligen lasse. Es schien darnach die Annahme, dass das Lab die Milch durch Säurebildung niederschlage, nicht haltbar und die Fällbarkeit des Caseins durch Lab eine specifische selbständige Wirkung des Labs

1) Schultze, Ann. Chem. Pharm. 71, 288.

2) Panum, Virchow's Arch. 4, 155.

5) Skrzeczka, quaeritur quomodo caseïnum ot natrum albuminatum pepsino afficiantar; diss, inaug. Regimonti 1855.

†) F. Simon, die Frauenmiloh nach ihrem chem. a. physiol. Verhalten, 27.

5) Solmi, J. pharm. 9, 265. 
zu sein, was durch die Untersuchungen von Heintz anscheinend bestätigt wurde.

Heintz ${ }^{1}$ ) coagulirte wie Selmi eine vorher durch Alkalizusatz alkalisch gemachte Milch durch Digestion mit Kälberlab bei Temperaturen von $50^{\circ}-62^{1} /{ }^{\circ}$ und fand nach der Coagulation ,die überstehende Flüssigkeit noch immer sehr deutlich alkalisch"; andererseits bestätigte er auch die Angabe Simon's, indem er zeigte, dass bei der Coagulation einer solchen Milch durch Lab bei Temperaturen von $37^{1} / 2-43^{3} / 4^{0}$ eine Flüssigkeit von saurer Reaction erhalten werde. Hieraus zieht Heintz den folgenden Schluss: Wenn es auch richtig sei, dass der Milchzucker der Milch durch Kälberlab bei Temperaturen von 371/9$43^{8} / 4^{\circ}$ in Milchsäure überführt und so das Caseïn durch Entziehung seiner Basis als unlöslich abgeschieden werde, so besitze das Kälberlab „doch andererseits die Eigenschaft, bei etwas höherer Temperatur die Coagulation desselben so zu veranlassen, dass sie der erzeugten Milchsäure nicht zugeschrieben werden kann" ${ }^{2}{ }^{2}$ ) Er betrachtet nur das auf letztere Art abgeschiedene Caseïn als die unlösliche Modification; denn das durch Säuren abgeschiedene Caseïn sei nur dureh Eutziehung der Basis unlöslich geworden, und da sich das durch Süuren gefällte Caseïn in höchst verdünntem Alkali wieder löst, so könne nur dasjenige Casein als coagulirt betrachtet werden, welches in einer alkalischen Flüssigkeit unlöslich ist. Heintz schloss also aus seinen Versuchen nicht blos, dass das Lab bei verschiedenen Temperaturen eine dem Wesen nach ganz verschiedene Wirkung ausübe, sondern er nahm auch an, dass das gefällte Caseïn in zwei Modificationen bestehe. In natürlicher Ausbildung dieser scheinbar begründeten Theorie verwarf $\mathrm{Hein} \mathrm{tz}^{\mathrm{B}}$ ) nun auch die Methode, Flüssigkeiten in der Weise auf Caseïn zu prüfen, dass man sie nach Zusatz von Milchzucker mit Kälberlab bei $30^{\circ}-40^{\circ}$

1) Heintz, Lehrb. d. Zoochem. 1853, 687.

3) a. a. 0.639 .

9) a. a. 0.701 . 


\section{Soxhlet: Beiträge zur physiologischen Chemie}

digerirt, weil durch die entstandene Milohsäure alle alkalischen Eiweisslösungen gefällt würden und stellte als „das wesentlichste Unterscheidungsmerkmal des Caseïns von anderen in verdünnten Alkalien gelösten, sonst unlöslichen Proteïnsubstanzen" - die Eigenschaft bin - „dass es auch aus alkalischen Lösungen in unlöslichen Zustande abgeschieden wird". In neuerer Zeit haben die Angaben von Heintz durch Völcker Bestätigung gefunden. Durch mehrere Versuchsreihen hat dieser gleichfalls darzuthun gesucht, dass die Wirkung des Labs eine von einer Säurewirkung verschiedene sei, indem auch er fand, dass eine stark alkalisch gemachte Milch durch das Lab bei höherer Temperatur coagulirt werde, ohne dass die alkalische Reaction der Flüssigkeit verschwindet. Es lässt sich aber die Annahme, das Lab wirke in höherer Temperatur anf das Caseïn in anderer Weise als in niederen, leicht als irrig erweisen und zeigen, dass das Caseïn auch in höherer Temperatur nur in Folge von Säuerung der Milch durch das Lab, auch bei beständig alkalischer Reaction der Flüssigkeit niedergeschlagen werde; ferner aber lässt sich gleichfalls zeigen, dass sich das Alkalialbuminat auch hierin nicht von dem Casein unterscheidet. Die Möglichkeit, dass eine Albuminatlösung nach der Gerinnung noch alkalisch reagirt, lässt sich leicht folgendermassen darthun. Setzt man za einer solchen Lösung neutrales und saures phosphorsaures Natron in einem solchen Verhältniss, dass das Albuminat gerade noch in Lösung bleibt, oder besser noch, dass das Lüsungsgemenge achon schwach opalescirend wird, und erwärmt, so scheidet sich das Albamin zum grössten Theil ab. Diese Fällung ist um so vollständiger, je weniger überschüssiges neutrales und je mehr saures Alkaliphosphat vorhanden ist. Durch das Erwärmen wird eine Umsetzung zwischen dem Alkalialbuminat und dem sauren Phosphat herbeigeführt, wobei dem Albuminat die Basis entzogen wird; ein Theil des sauren Phosphats geht aber dabei in das nentrale Phosphat über, dessen alkalische Reaction sich auch neben dem noch vorhandenen sauren Phosphat bemerklich machen muss. 
Lässt man andererseits die Fällung einer reinen Albuminatlösung durch Milchsäure zu Stande kommen, so erhält man gleichfalls eine alkalisch reagirende Flüssigkeit, wenn man nicht mehr Milebsäure einwirken lässt als gerade zur Fällung des Eiweisses nöthig ist. Der Ueberschuss an Milchsäure lässt sich leicht vermeiden, wenn man das Albuminat nicht vollständig ausfällt. Es entsteht dabei milchsaures Alkali, welches demnach wie z. B. das essigsaure, das citronensaure Alkali alkalische Reaction besitzen muss. Hat man aber der Albuminatlösung vorher noch ein Alkali zugesetzt, wie die letztgenannten Forscher thaten, so bildet sich um so mehr milchsaures Salz und reagirt dann diese Flüssigkeit nach nicht ganz vollständiger Ausfällung um so mehr alkalisch. Prüft man endlich die eine oder die andere Flüssigkeit, nachdem man die Gerinnung in der Wärme herbeigeführt, unmittelbar darauf, so lange sie noch heiss ist, so tritt die alkalische Reaction wegen der schon besproohenen Einwirkung der Wärme auf den Lakmusfarbstoff noch stärker hervor.

Die geschilderten Verhältnisse sind aber ganz dieselben, welche bei der Gerinnung der Milch durch Lab stattfinden. Das Lab erzeugt aus dem Milchzucker Milchsäure, durch welches das in der Milch enthaltene neutrale Alkaliphosphat in das saure übergeführt wird. Hat sich in Folge dieser Säuerung dasjenige Verhältniss zwischen dem neutralen und sauren Phosphat hergestellt, bei welchem das Albuminat in der Kälte eben nur noch gelöst ist, and ist die Temperatur hoch genug, so wird der $\mathrm{Ei}$ weisskörper gefällt, während die Flüssigkeit noch alkalisoh ist. Neben der alkalischẹn Reaction lässt sich aber noch saure nachweisen, welche jenen Forschern entgangen ist. Blos snuer wird eine solche Flüssigkeit reagiren, wenn die Säurebildung über diesen kritischen Punkt bereits hinausgegangen ist. Als Beleg führe ich nun folgende Versuche an.

Milch, die durch Selbstsüuerung jenen Săuregrad erreicht hatte, wo sie in der Kälte noch flüssig war, aber beim Erwärmen auf $50^{\circ}$ gerann, reagirte vor dem Journ. f. prakt. Chemie [3] Bd. 6. 


\section{Soxhlet: Beiträge zur physiologischen Chemie}

Coaguliren nur sauer (weil nur noch wenig neutrales Phosphat vorhanden war), nach dem Coaguliren sauer und schwach, aber deutlich wahrnehmbar alkalisch. Eine Probe derselben Milch, welche dureh Säurezusatz in jenen Säurezustand versetzt worden war, zeigte dasselbe Verhalten. Eine andere Probe dieser Milch, die vorher mit kohlensaurem Natron stärker alkaliscb gemacht und bis zum Eintritti jenes Säuregrades der Selbstsäuerung überlassen worden war, reagirte nach dem Coaguliren durch Erwärmen auf $50^{\circ}$ stärker alkalisch als die ohne Zusatz ron kohlensaurem Natron (wegen des grösseren Gehalts an milchsauren Alkalien). Eine Probe dieser stärker alkalisch gemachten Milch wurde im Wasserbde bei $60^{\circ}$ der Selbstsäuerung überlassen; nach 28 Stunden war sie geronnen und reagirte schwach alkalisch, eine Stunde später dagegen nicht mehr.

Diese Versuche wurden mit den gleichen Resultaten mit einer aus Kalialbuminat bereiteten künstlichen Milch wiederholt. Durch Iuösen in Aether gereinigte Butter wurde mit einer $3^{\mathbf{r}} / \mathbf{2}$ procentigen Kalialbuminatlösung emulgirt, dann mit Milchzucker versetzt, ferner mit einer Lösung von phosphorsaurem Natron, der bis zur amphoteren Reaction Milchsäure hinzugefügt war und endlich mit etwas kohlensaurem Natron. Von dieser künstlichen Milch wurde eine Probe auf $50^{\circ}$ erwärmt und dann verdünnte Milchsäure vorsichtig bis zu nicht ganz vollständig erfolgter Coagulation zugesetzt. Eine zweite Probe wurde mit etwas Labflüssigkeit versetzt und ebenfalls bei $50^{\circ}$ digerirt. Beide Flüssigkeiten reagirten nach der Gerinnung schwach aber deutlich alkalisch.

In allen diesen Versuchen war neben der alkalischen Reaction auch saure vorbanden, ebenso wie diess der Fall war, wenn alkalisch gemachte Milch durch Lab bei $50^{\circ}$ congulirt wurde; und als eine mit kohlensaurem Natron bis zurn Verschwinden der sauren Reaction versetzte Milch gleichfalls durch Lab bei. 50 $0^{\circ}$ zum Coaguliren gebracht wurde, reagirte sie ebenfalls sauer und alkalisch: ein Be- 
weis dafür, dass die Coagulation durch Lab auch bei höheren Temperaturen nur durch Säurewirkung erfolgt.

Eine Bestätigung für die Ansicht, dass die Coagulation des Caseïns in der Milch durch Lab auch in höheren Temperaturen vur dadurch erfolgt, dass sich aus dem Milchzucker der Milch Milchsäure bildet, welche die $\Lambda$ bscheidung des alkalifreien Eiweisskörpers bewirkt, bieten folgende Versuche. Von frischer Milch wurden je $100 \mathrm{Cc}$. in die Kölbchen A, B, C, D, E, F und $\mathbf{G}$ gebracht und jede dieser Portionen mit $1 \mathrm{Cc}$. eines sehr verdünnten. klaren Infusums der Schleimhaut eines Kälbermagens versetzt. Zu A geschah kein weiterer Zusatz, zu B wurde 1 Cc. zu $\mathrm{C} 2 \mathrm{Cc}$. und zu $\mathrm{D} 3 \mathrm{Cc}$. einer sehr verdünten Milchsäure zugesetzt; die Milch in $\mathbf{E}$ wurde mit $1 \mathrm{Cc}$. sehr verdünnter Lösung von kohlensaurem Natron versetzt, die in $\mathbf{F}$ mit $2 \mathrm{Cc}$. und die in $\mathbf{G}$ mit $3 \mathrm{Cc}$. dieser Lösung vermischt. Alle 7 Kölbchen wurden gleichzeitig in ein Wasserbad gebracht und die Temperatur des Wassers auf $50-52^{\circ}$ erbalten. Die Mileh war geronnen in

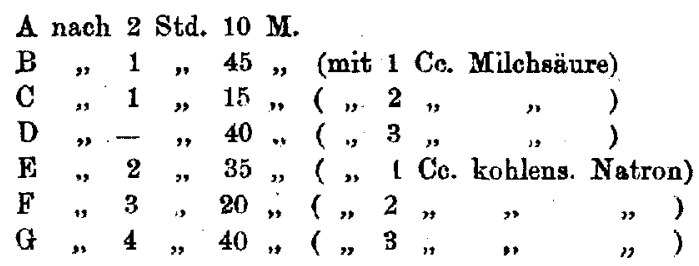

d. h. die Mileh gerann desto später je mehr Alkali in derselben anwesend war.

An dieser Stelle will ich noch auf einen Fall aufmerksam machen, in welchem das Caseïn (wie das Alkalialbuminat) in alkalischer Flüssigkeit gefällt wird, ein Fall der allgemein bekannt, aber in dieser Bedentung noch nicht aufgefasst ist, die Abscheidung des Caseins bei seiner quantitativen Bestimmung in der Milch. Ist eine Milch durch Selbstsäuerung oder durch Essigsäurezusatz so sauer geworden, dass sie schon in der Kälte durch Kohlensäure gefäl!t wird, so findet man nach so vollzogener Fäliung die Flüssigkeit noeh stärker alkalisch, als wenn 
36 Soxhlet: Beiträge zur physiologischen Chemie

das Caseïn durch Lab niedergesehlagen wurde, und doch ist jene Fällung viel vollständiger als die durch Lab. Aus diesen Beobachtungen ergiebt sich also, dass das Caseïn, wie das Kalialbuminat, auch in alkalischer Flüssigkeit abgeschieden werden kann, und dass diese Fällung, wenn sie durch Lab hervorgebracht wird, gleichfalls auf einer Säurewirkung beruht.

Man hat aber noch auf eine Eigenschaft aufmerksam gemacht, durch welche sich das durch Lab gefällte Caseïn von dem durch Säuren niedergeschlagenen unterscheiden soll. Man hat angegeben, dass sich das durch Säuren gefällte Caseỉn iu koblensauren Alkalien leicht löse, das durch Lab gefällte dagegen entweder nicht oder doch erst nach anhaltendem Kochen. $\left.{ }^{2}\right)$ Die Angabe ist dann richtig, wenn man sie auf das klumpige Labcoagalum und den feinflockigen Säureniederschlag bezieht. Durch das Lab wird das Caseïn in ganzer Masse gefällt und man erhält ein zusammenhängendes Gerinnsel; es ist an sich klar, dass sich ein solehes weit langsamer lösen kann, als ein feinflockiger Niederschlag. Sorgt man aber dafür, dass das Caseïn durch das Lab gleichfalls in Flocken getällt wird, so löst sjeh dasselbe in kohlensauren Alkalien eben so leicht wie das durch Säuren abgeschiedene. Ein solches feinflockiges Gerinnsel habe ich erhalten, als ich Milch mit so viel Labflüssigkeit versetzte, dass sie in 2-3 Minuten gerinnen konnte, und nun das Gemiseh unter heftigem Schütteln auf $50-55^{\circ}$ oberhalb der Gasflamme erwärmte. Dasselbe löste sich schon in so wenig. kohlensaurem Natron, dass die Lösung noch saure Reaction zeigte.

Welcher Art die wirksame Substanz des Labs sei, lässt sich vor der Hand noch nicht mit Bestimmtheit entscheiden, doch gehört sie wahrscheinlich den sogenannten chemischen Fermenten an. Sie ist nur dem Labmagen der Wiederkäuer eigenthümlich. Die Angabe, dass auch andere

1) Handwörterbueh d. Chem. von Liebig, Poggendorff etc. 1. Auf., 3, 229. 
thierische Gewebe oder Flüssigkeiten eine Substanz enthalten, durch welche die Milch zur Gerinnung gebracht werden kann, darf nicht auf einen Gehalt dieser an Lab bezogen werden, denn diese enthalten saure Salze und freie Säure, durch welche allein, namentlich in höherer Temperatur die Milch coagulirt wird. Fremy $y^{1}$ ) zeigte vom Lab zuerst, dass es den Milchzucker in Milchsäure verwandelt. Fine Zeit lang hielt man diese Substanz für identisch mit dem Pepsin (so Skrzeczka), bis Brücke nachwies, dass die Milch durch reines Pepsin nicht gefallt wird. Versetzt man, wie ich gethan habe, Milch mit dem Auszug der Magenschleimhaut eines während der Verdauung getödteten Hundes, so gerinnt sie unter sonst gleichen Umständen nicht früher, als eine andere reine Probe dieser Milch. Die Eigenschaft des Labs, den Milchzucker in Milchsäure $z u$ verwandeln, bei dem Umstand, dass man dasselbe im Magen saugender Kälber antrifft, brachte mich auf den Gedanken, dass diese Gährung vielleicht nur durch das von Pasteur aufgefundene organisirte Milehsäureferment hervorgebracht werde, das in den Magen gelangen, und sich daselbst in einer zu seiner Entwickelung gedeihlichen Umgebung festsetzen könnte. Ich habe einen jungen Hund 13 Tage lang nur mit Milch gefüttert ond dann während der Verdauung getödtet; der wässerige A uszug aus der Schleimhaut seines Magens beschleunigte indess die Gerinnung der Milch nicht im Entferntesten. Auch konnte ich in der durchfiltrirten fast klar erhaltenen, kräftig wirkenden Labflüssigkeit aus Kälbermagen, selbst bei 500 facher Vergrösserung nichts Organisirtes wahrnehmen. Grosse, stark lichtbrechende, punktirte Kugeln erwiesen sich nach ihrer Löslichkeit in Aether als Fett. Durch Kochen büsst das Lab seine Wirksamkeit ein, dagegen nicht, wenn man es durch Alkohol fällt und den Niederschlag einige Zeit unter absolutem Alkohol stehen lässt; es gleicht also hierin den nicht organisirten Fermenten. Geringe Mengen Aetzkali, zu Lablösung gesetzt, heben dessen Wirkung auf,

1) Fremy, J. pharm. 25, 599 and Ann. Chew. Pharm. 31, 188. 
38 Soxhlet: Beiträge zur physiologischen Chemie

während Ammoniak und kohlonsaure Alkalien, diess nicht thun. Dieses von Cl. Bernard und Schiff für andere unzweifelhaft chemische Fermente angegebene Verhalten, scheint besonders flir die nicht organisirte Natur dieses Fermentes zu sprechen.

\section{Die Filtrirbarkeit des Caseïns durch Thonzellen.}

In jüngster Zeit hat $W . Z^{2} a^{n}{ }^{1}$ zwei weitere vermeintliche Unterschiede zwischen Alkalialbuminat und Caseïn angegeben. Der eine derselben wurde gefunden, als Milch oder Kalialbuminatlösung unter Anwendung der Wasserluftpumpe durch Thonzellen filtrirt wurden, wobei sich ergab, dass aus der Milch in das Filtrat kein Caseïn überging, während eine reine Kalialbuminatlösung „eben so rasch als Serum - und Lactalbumin filtrirte"، Diese Verschiedenheit hält Zahn ,für ein wesentliches Unterseheidungsmoment". Obwohl dieses Unterscheidungsmerkmal bereitwillige Aufnahme in die neuesten Lehrbücher ${ }^{2}$ ) gefunden hat, so scheint ihm von vornherein doch nicht mehr Werth beigelegt werden zn können, als einer Unterscheidung zweier Eiweisskörper z. B. nach ler Form der Niederschläge. Ebenso wenig, wie man das klumpig coagulirte Caseïn für eine andere Substanz ansehen darf, als das flockig abgeschiedene, wird man eine durch Thonzellen filtrirende Eiweisslösung für chemisch verschieden halten dürfen von einer anderen, welche diess nicht thut, weil auf den Ausfall des Versuchs eine Anzahl bekannter und unbekannter Nebenumstände von Einfluss sein könnén; namentlich dann, wenn man von der einen Substanz eine reine Lösung anwendet, von der andern aber eine solehe, welche (wie die Milch) noch andere Substanzen gelöst und suspendirt enthält. Eine Wiederholung der Zahn'schen Versuche

1) W. Zah n, Pfüger's Arch. f. Physiol. 1869, 598.

2) Funke, Lehrb. d. Physiologie 1871. - v. Gorup.Besanez, Anleitg. z. zoochem. Analyse. 3, Auf., 1871, 101. 
hat denn auch das erwähnte Unterscheidungsmerkmal als unhaltbar erwiesen.

Zumächst hat sich dabei ergeben, dass sich Kalialbuminatlösung nicht unter allen Umständen durch Thonzellen filtriren lässt. Die Filtrirbarkeit reiner Kalialbuminatlösung uiberhaupt ist abhängig ron der Dickwandigkeit und Porosität der Thonzellen. Wïhrend ich bei der. Filtration von verschieden concentrirten Kalialbuminatlösungen durch dichtere und dickwandige Thonzellen, auch nach 20stündigem Filtriren in Filtrate mittolst der Xanthoproteinsäurereaction kaum Spuren von Eiweiss nachweisen konnte, konnten schon mit verdünnter Essigsüure in Fil trate, das mit dünnwandigen und poröseren Thonzellen erhalten wurde, deutlich erkennbare Mengen Kalialbuminat anfgefunden werden. Eine genügende flockige $\Lambda$ bscheidung des Eiweisskörpers im Filtrate mittelst Essigsäure konnte ich jedoch nur mit so dünnen und porösen Thonzellen erhalten, die ein Aufziehen der Kautschukkappen zur Herstellung der Verbindung mit der Wasserluftpumpe, ihrer Zerbrechlichkeit wegen, gar nicht gestatteten. Um in diesem Falle diese Verbindung herzustellen, habe ich ein Verfahren angewendet, dessen sich Dr. Paschutin zur Filtration von Verdauungstermenten bediente. Die Zelle wurde mit einer durchbohrten starken Glastafel bedeckt, unter welcher eine Kautschukplatte lag, um die Verbindung dicht zu machen. In der Durchbohrung der Glastafel war mittelst eines Kautschukpropfens ein Glasrohr eingesetzt, an welches der Schlauch der Wasserluftpumpe gesteckt wurde. Beim Evacuiren wurde die Glastafel dann durch den Luftdruck auf die Zelle aufgepresst.

Wurde durch ebenso dünnwandige Zellen dagegen Milch filtrirt, so konnte im Filtrat durch Essigsäure kein Niederschlag erhalten werden, und es besteht demnach in der That eine Verschiedenbeit zwischen der Filtrirbarkeit einer Kalialbuminatlösung und der Milch. Aber dieser Unterschied lässt sich nicht auf eine Verschiedenheit des Caseins vom Albuminat beziehen, denn er verschwindet sofort, wenn man statt der reinen Kalialbuminatlösung eine solche 


\section{Soxhlet: Beitragge zur physiologischen Chemie}

verwendet, in welcher durch Schütteln mit geschmolzener Butter bei $30-40^{\circ}$ Fett fein vertheilt wurde. Fine solche Emulsion lïsst durch die dünnwandigen Zellen den Eiweisskörper ebenso sehwer hindurch wie die Mileh; im Filtrat lässt sich durch Essigsäure keine Spur eines Eiweisskörpers nachweisen, und nar bei anhaltendem Filtriren treten im Filtrat Spuren von Eiweiss auf, welche sich nur durch Salpetersäure und Ammoniak nachweisen lassen.

Aus den Zahn'schen Versuchen ist also nicht mehr zu schliessen, als dass sich reine Kalialbuminatlösungen und solche, die mit Fett emulgirt sind (wie die Mileh), beim Filtriren durch eine Thonzelle wohl verschieden verhalten, nicht aber, dass Kalialbuminat und Caseīn nicht identisch seien.

\section{Die Fälbarkeit der Milch durch kohlensaures Natron.}

Zahn') hat noch ein zweites Unterscheidungsmerkmal beider Eiweisskörper angegeben, das darin bestehen soll, dass die Milch durch eine concentrirte Lösung von kohlensaurem Natron gefällt werde, während Kalialbuminatlösung dieses Verhalten nicht zeige. Auch dieser Unterschied ist nicht in einer Verschiedenheit des Kalialbaminats und des Caseïns begründet, sondern erklärt sich einfach daraus, dass dem Caseîn in der Mileh noch andere Substanzen. beigemengt sind. Von welchem Einfluss selbst geringe Beimengungen auf die Reaction der Fiweisskörper sind, zeigen sehr deutlich reine Kalialbuminatlösungen und solche, welche Spuren Kochsalz, Chlorcalcium oder phosphorsaures Natron enthalten in ihrem Verhalten za Alkohol. Während nämlich die reinen Lösungen durch Alkohol nicht verändert, werden, wird in den salzhaltigen das Albuminat durch Alkohol fast vollständig in Flocken abgeschieden. Wollte man blos nach dieser Reaction urthejlen, so wäre man in diesem Falle ebenso berechtigt, den

3) 3. a. 0 , 
Eiweisskörper einer reinen, und den einer minimale Salzmengen enthaltenden Kalialbuminatlösung für ganz verschiedene Körper zu halten; man könnte dies um so eber, als eine reine Kalialbuminatlösung mit einer solchen, die eine geringe Menge Kochsalz enthält, mit mehr Recht verglichen werden kann, als eine reine Kalialbuminatlösung mit einer solchen, die mit Fett emulgirt ist, Milchzucker, ver'schiedene Salze und noch andere mehr oder weniger gekannte Körper enthält. $\mathrm{Da}$ in der That die Milch ihrea Salzgehaltes wegen darch Alkohol gefällt wird, so könnte die Fällbarkeit durch Alkohol ebenso gat, aber nicht mit mehr Recht, als Unterscheidungsmerkmal für Caseïn und Kalialbuminat angegeben werden.

Die Eigenschaft, die Milch zu fällen, kommt nicht blos dem kohlensauren Natron zu, sondern nach Braconnot") auch Aetzalkalien, und wie ich gefunden habe, dem phosphoraauren Natron. Nun sind aber diese Salze Lösungsmittel für das Casein, und wenn man sich die Füllbarkeit der Milch durch diese erklären will, so wird man annehmen müssen, dass das Caseïn nur mechanisch niedergeschlagen wird, $d . h$. dass durch jene Reagention gewisse Salze der Milch gefällt werden, und dass durch diese Niederschläge das Caseïn, welches in der Milch weniger in Lösung als in stark aufgequollenem Zustand. enthalten ist, mit niedergerissen werde. Versetzt man Milchserum, das durch Ausfällen der Milch mit Säuren und Kochen oder mittelst Filtration durch Thonzellen gewonnen wurde, mit kohlensaurom, phosphorsaurem oder Aetznatron, so erhält man einen reichlichen Niederschlag von phoephorsaurem Kalk, welcher ebenso in der Milch selbst entstehen, und der in der Milch Casein mit einschliessen muss, wie in den Versuchen von Brücke"), welche dieser zur Reindarstellung des Pepsins angestellt hat, der phosphorsaure Kalk das Verdauungsferment einschloss. Für die Richtigkeit dieser Anschaung spricht

7) Braconuot, in Gmelin Handb. 7, 2259.

7) Brüoke, Wien. Akad.-Ber. 49, II Abth., 601. 
42 Soxhlet: Beiträge zur physiologischen Chemie

die Angabe Braconnot's, dass sich in dem durch Aetzalkalien in der Milch erhaltenen Niederschlage das Casein wieder beim Auswaschen mit Wasser löst, eine Angabe, welche nach meinen Firfahrungen auch bei den durch kohlensaure und phosphorsaure Alkalien erhalteneri Niederschlägen zutrifft.

Ein ähnliches Verhalten, wie die natürliche, zeigt anch eine künstliche aus Kalialbuminat bereitete Milch. Diese wurde bereitet aus einer $4^{1 / 2}$ procentigen Kalialbuminatlösung, welche bei $40^{\circ}$ mit Butter geschüttelt wurde, die dureh Lösen in Aether gereinigt worden war. Zu dieser Emulsion von milchgleichem Ansehen wurde noch so viel Chlorcalcium geretzt, als dem Kalkgehalt der Milch $(0,7$ p.C. nach der Aschenanalyse von Weber) entspricht. Auf Zusatz von phosphorsanrem Natron entstand nun ein grobllockiger Niederschlag von genar demselben Ansehen, wie der durch kohlensaures Natron in der Milch erzeugte, und auch sus diesem liess sich auf dem Filter das Albumin durch Wasser auswaschen. Der in der künstlichen Milch entstandene Niederschlag von phosphorsaurem Kalk hatte also Kalialbuminat und Fett mit niedergerissen, wie der in der natïrlichon Milch durch kohlensaures Natron erzeugte das Caseïn und das Fett. Hätte man die Verhältnisse der natürlichen Milch genau in der künstlichen nachbilden wollen, so hätte man letzterer ein lösliches Kalkphosphat in der Menge zusetzen müssen, wie der Kalkgehalt der Milch verlangt und mit kohlensaurem Natron făllen müssen. Dazu hätte sich nur das saure Kalkphosphat geeignet, welches aber deshalb nicht anwendbar ist, weil es das Kalialbuminat fällt. Die Phosphorsänre cler Milchasche scheint nicht ihrer ganzen Menge nach als solche in der Milch enthalten zu sein, weil sich sonst nicht erklären liesse, wie neben ihr in der amphoter reagirenden Fluissigkeit so viel Kalk gelöst sein kann. Alle meine Versuche, eine amphotere Salzlösung herzustellen, welche Kalk und Phosphorsäure in demselben Verhältniss enthielt wie die Milch, und Kalialbuminat nicht fällte, sind fehlgeschlagen. Vielleicht enthält die 
Milch eine organische Phosphorsäure, deren neutrales Kalksalz löslich ist (Glycerinphosphorsăure?)

Für meinen Zweck ist diess jedoch ganz gleichgültig, da es nur darauf ankam, in der künstlichen Milch einen Niederschlag von phosphorsaurem Kalk zn erzeugen.

Bei diesen Versuchen stellte sich heraus, dass man einen Niederschlag in denselben groben Flocken, wie in der natürlichen Milch, nur bei Gegenwart von Fett erhält. Eine nur mit.Chlorcaleium. versetzte Kalialbuminatlösung gab mit phosphorsaurem Natron nur einen feinen Niederschlag; das Fett scheint also, indem es gleichzeitig mit dem Albumin niedergerissen wird, das Volumen der Flocken zu vergrössern und ihnen ihr eigenthümlichess Ansehen zu varleihen.

Dass übrigens die Bildung des Kalkphosphates Bedingung für das Zustandekommen der flockigen Fällung ist, ergiebt sich daraus, dass eine Emulsion von Kalialbuminat und Fett allein, durch phosphorsaures und koblensaures Natron nicht gefullt wird; ebenso wenig wie Caseïn, das durch Essigsäure gefällt, ausgewaschen und in sehr verdünntem Alkali wieder gelöst wurde. Löst man dagegen den durch Essigsäure in der Milch entstandenen Niederschlag in dem Milchserum durch sehr verdünntes Alkali wieder auf, so verhält sich diese Jösung gagen die genanıten Fällungsmittel ganz wie die ursprüngliche Milch.

Bemerkenswerth ist ubrigens noch, dass zum Fällen der natürlichen ale auch der künstlichen Milch bedeutend mehr Reagens nöthig ist, als dem Kalkgehalt der Lösung: entspricht, werin man eine groblockige Ausscheidung erhalten will; diese ist um so grobflockiger, je mehr Reageus auf einmal zugesetzt wird. Dieser Unstand weist gleichfalls darauf hin, dass die Fällung des Caseïns durch diese Reagentien nur eine mechanische und keine chemische ist. 


\section{Soxhlet: Beiträge zur physiologischen Chemie}

\section{Das Verhalten des Caseïns und des Albuminats gegen Alkalliauge.}

Der ungleich gewichtigste Einwand, welcher gegen die Identität des Kalialbuminats mit Caseïn erboben wurde, ist der Hoppe's "), dass die Albuminate ,vom Caseïn darin verschieden sind, dass dieses bei der Behandlung mit Kalilauge Schwefelkalium bildet, während die bereits gebildeten Albuminate diess nicht thun." - In der neuesten Auflage seines Handbuches der physiol. und pathol. ehem. Analyse ${ }^{2}$ ) fuihrt diess Hoppe in der Synopsis der Albuminstoffe ebenfalls an:

1) „Das Caseïn giebt beim Stehen oder schneller beim Erwärmen mit Aetzkalilauge Schwefelkalium: 2) Alkalialbuminate (Proteïne) geben mit Kalilauge kein Schwefel-

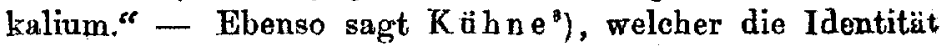
jener beiden Eiweisskörper bestimmt ausspricht, ohne jedoch den Einwand Hoppe's zu berücksichtigen, von dem Albumin, welches durch Neutralisiren einer Lieberkühn'schen Kalialbuminatlösung abgeschieden wird: „der Schwefel kann aus diesem Albumin nicht durch siedende Kalilauge abgespalten werden, ist also nicht durch Kochen mit Kali und Bleisalzen an der Schwefelbleireaction zu erkennen, sondern nur durch Verbrenuen mit Salpeter, wobei schwefelsaures Kali entsteht"

Meine Versuche, welche die eingehendere Prüfung dieser Angaben bezweckten, ergaben jedoch, dass das Caseïn und das Kalialbuminat bei der Behandlung mit Kalilange die vollkommenste Uebereinstimmung zeigen. Beide bilden, mit concentrirter Kalilauge behandelt, sowohl in. der Kälte, als in der Wärme, Schwefelkalium, während sehr verdünnte, eben nur zum Lösen jener gefällten Eiweisskörper hinreichende Mengen Kalilauge, eine Schwefelkaliumbildung nicht veranlassen Die Bildung von Schwe-

7) Hoppe, Chem. Centr. 1865, 787 (Orig.-Art.).

7) Hop pe-Seyler, Handb., 3. Anfl, 1870, 196, 197.

s) Kü h ne, Lehrb. d. phys. Chemie 1868, 176. 
felkalium wurde bei meinen Yersuchen nachgewiesen, durch die Schwefelwasserstoffentwicklung, welche beim Versetzen des mit Kalilauge behandelten Eiweisskörpers mit Essigsäure eintrat. Um auch geringe Mengen so entstandenen Schwefelwasserstoffs nicht zu übersehen, warden die Ver. suche in folgender Weise angestellt.

Die Behandlung des betreffenden Eiweisskörpers mit Kalilauge wurde in einem $1 / 2$ Liter-Kolben vorgenommen, welcher mit einem dreifach durchbohrten Kork verscblossen war. Durch die eine Bohrung ging ein bis an den Boden des Kolbens reichendes Glasrohr, welches am oberen Ende durch ein Stückchen Kautschukschlauch mit einem Trichter in Verbindung stand. Durch einen Quetschbahn konnte diese Verbindung aufgehoben und so das Glasrohr abgeschlossen werden. Durch die zweite Bohrung ging ein ebenfalls bis an den Boden reichendes Rohr, welches knieförmig gebogen war und dessen ausserhalb des Kolbens befindlicher Schenkel mit einer Bleioxydkali enthaltenden Waschflasche in Verbindung stand. Ein in die dritte Bobrung passendes knieförmiges Glasrohr, dessen einer Schenkel nur wenig in den Hals des Kolbens hineinragte, verband diesen Kolben mit einem kleinen $2 \mathrm{Cm}$. weiten Glascylinder, welcher mit einem doppelt durchbohrten Kork versehen war. Durch die eine Bohrung ging bis an den Boder der eine Schenkel eines knieförmigen Rohres, während der andero durch ein kurzes Stückchen Gummirohr mit dem Knierohr des Kolbens verbunden war. Ein zweites, ebensolches Rohr ragte durch die zweite Bohrung etwas in den Glascylinder hinein und diente zur Verbindung des ganzen Apparates mit der Wasserluftpumpe, welche als Aspirator diente. Am Boden des Glascylinders befand sich knapp unterhalb der Mündung des einen Glasrohrs eine Lage passend ausgeschnittener Filtrirpapierstückchen, welche mit Bleizuckerlösung und Ammoniak befeuchtet waren.

Wurde nun in den Kolbea, in welohem sich durch die Einwirkung, der Kalilauge auf den Eiweisskörper Schwefelalkalium gebildet hatte, durch den Trichter concentrirte Essigsäure in hinreichender Menge (bis zur stark- 


\section{Soxhlet: Beiträge zur physiologischen Chemie}

sauren Reaction) gegossen, mittelst des Quetschhahns das Trichterrohr verschlossen und der Hahn der Wasserluftpumpe geöffnet, so drang ein Luftstrom durch den Apparat, der durch die Bleioxydkalilösung von möglicherweise anwesendem Schwefelwasserstoff gereinigt, den in den $\mathrm{Kol}$ ben nun entstandenen Schwefelwasserstolf mit fortriss und die in den Cylinder befindlichen Papierstückehen bestreichend, auf diesen jene schillernd braune Färbung, herrührend von entstandenem Schwefelblei, verursachte. Auf diese Weise können überhaupt kleine, auf andere Weise nicht mehr nachweisbare Mengen Schwefelkalium nachgewiesen werden, wenn sie sich, ähnlich wie hier in undurchsichtigen Flüssigkeiten anwesend, durch geringe Niederschläge oder Farbenveränderungen nicht erkennen lassen. Am zuverlässigsten ist es, zur Entwickelung des Schwefelwasserstoffs nur concentrirte Essigsäure zu verwenden; so gab z. B. Schwefelsäure, welche zur Zersetzung des Schwefelkaliums, das von Caseïn herrührte, angewendet wurde, oft keine Schwefelwasserstoffreaction, weil wahrscheinlich aus den Chloriden der Milchsalze Chlorwasserstoff entwickelt wurde, welches die Bildung von sich schwerer schwärzendem Chlorblei veranlasste, während Essigsäure in solchen Fällen immer eine Bräunung des Bleizuckerpapiers hervorrief. Aus dem gleichen Grunde ist die Chlorwasserstoffsäure nicht anwendbar.

Bleioxydkali wurde zum Waschen des Luftstromes, statt des ebenfalls genügenden Kalis angewendet, um ein Urtheil über den Gehalt der Luft an Schwefelwasserstoff zu gewinnen, und so den Versuch abzubrechen, wenn sich dieser als erheblich erwiesen bätte.

$\mathrm{Zu}$ den Versuchen wurden immer nicht zu geringe Mengen des Eiweisskörpers verwendet, um deutliche Reactionen zu bekommen; etwa so viel, dass der Kolben zum 4.-5. Theil von dem dickbreiigen Eiweissniederschlage erfïllt war. Caseiin aus der Milch mit Essigsäure gefällt und. eben nur in sehr verdünntem Alkali gelöst, gab, auch wenn gekocht wurde, nach der beschriebenen Methode keine Schwefelwasserstoffreaction. Ebenso der durch 
Neutralisiren einer Kalialbuminatlösing erhaltene Albuminniederschlag, wenn er eben nur in verdünntem Alkali gelöst und so behandelt wurde. Mit concentrirter Kajilauge in der Kälte behandelt gałen beide Körper, sowohl gefälltes Casein als Lieberkühn'sches AJbumin, nach dieser Methode Schwefelwasserstoffreaction. Die Intensität dieser Reaction war, wenn die Menge der verwendeten Eiweisskörper, der Kalilauge und die Dauer der Einwirkung annähernd gleiche waren, bei beiden Körpern nicht merklich verschieden. Zusatz von mehr Kalilauge, längere Dauer der Einwirkung, Erhöhung der Temperatur während der Einwirkung, hatte intensivere Schwefelwasserstoffreaction bei beiden zur Folge. Bevor das Kalialbuminat auf die Sehwefelkaliumbildung untersucht wurde, wurde eine gleich grosse Menge des durch Ausfällen mit Essigsäure erhaltenen Niedersehlages, ohne mit Kalilauge behandelt zu werden, in den Apparat gebracht und aach Zusatz conc. Essigsäure, wie beschrieben, auf Schwefelwasserstoff gepruft; es geschah diess, wm sich zu vergewissern, dass jene Schwefelwasserstoffreaction nur eintritt, wenn der Eiweisskörper mit Kalilauge behandelt war. Im ersteren Falle zeigte sich nie eine Spur Schwefelwasserstoff. Ueberdiess wurden die Albuminniederschläge aus Kalialbuminat vorher noch gut gewaschen. Die verwendete Kalilange war ganz frei von Schwefelkalium.

Der durch Essigsäurezusatz aus den Lösungen der Eiweisskörper, welche mit concentrirter Kalilauge behandelt waren und Schwefelkaliura gebildet hatten, abgeschiedene Eiweisskörper wurde abfiltrirt, andauernd mit Wasser gut gewaschen, ein Theil erst so in den Apparat gebracht, mit etwas Essigsäure versetzt und geprüft, ob er noch Schwefelwasserstoffreaction verursache. Da diess nicht der Fall war, wurde der andere Theil wieder mit concentrirter Kalilauge behandelt und geprüft, ob dieser Körper, der schon einmal Schwefelkalium gebildet hatte, noch einmal Schwefelkalium bilden wiirde. In der That warde anch nach Essigsüurezusatz, Bräunung des Bleipapiers erhalten. Auch hier verhielten sich die Eiweisskörper, welche durch 
48 Soxhlet: Beiträge zar physiologischen Chemie

Behandeln von gefälltem Caseïn oder Lieberkühn'schem Albumin mit concentrirter Kalilange in der Kälte, Fällen durch Essigsäure und Auswaschen mit Wasser erhalten wurden, gleich; sie gaben, noch einmal mit Kalilauge behandelt, Schwefelkalium; ja diese Schwefelkaliumbildung war auch bei jenen Eiweisskörpern in nicht merklich geänderter Intensität bemerklich, welche durch mehrnaliges abwechselndes Behandeln mit concentrirter Kalilange, Ausfällen mit Essigsäure und Auswaschen mit Wasser erhalten wurden. Sowobl Casein, als Lieberkühn'sches Albumin, welche auf solehe Weise viermal der Behandlung mit concentrirter Kalilauge unterzogen warden, zeigten in annähernd gleichen Mengen verwendet, keine merklich verschiedene Intensität der Schwefelwasserstoffreaction, wenn sie zum fünften Male mit concentrirter Kalilauge in der Kälte behandelt und in jenem Apparat wieder durch Essigsäure ausgefällt wurden. Auch hier wurden die noch nicht zum fünften Male mit Kali behandelten Eiweissniederschläge vorher auf freien Schwefelwasserstoff geprüft und davon frei befunden.

Ans dem Mitgetheilten geht sonach hervor, dass sowohl Caseïn als Lieberkühn'sches Kalialbuminat mit Bezug auf das Verhalten, durch Behandlung mit Kalilauge Schwefelkalium zu bilden, gar keine Abweichung zeigen, und dass demnach die Angaben Hoppe's und Kühne's zu berichtigen sind.

Es scheint überdiess, als ob die Einwirkung des Kalis auf die Eiweisskörper nicht so aufzufassen sei, dass sich Schwefelkalium und ein schwefelärmeres Albuminat bilde, sondern dass ein Theil des Eiweisses durch das Kali vollständig in entferntere Producte zerlegt wird, deren eines Schwefelkalium ist, während der durch Säuren wieder gefällte Eiweisskörper als von gleichem Sohwefelgehalt, wie der ursprüngliche zu betrachten wấre. 


\section{Die Circumpolarisation des Caseïns und Kali- albuminats.}

Viel weniger Gewicht als auf jenes Verhalten der beiden Eiweisskörper bezüglich der Schwefelabspaltung ist auf die Verschiedenheit zu legen, welche sie nach Hopp 's $^{1}$ ) Angaben in der Drehung des polarisirten Lichtstrahles zeigen sollen, deshalb, weil eine hinlänglich genaue $\mathrm{Be}$ stimmung der specifischen Drehung der Eiweisskörper vor der Hand noch nicht ausgeführt werden konnte. Vergleicht man die bis jetzt vorliegenden Augaben, so gewinnt man leicht die Ueberzeugung, dass sich aus dem gefundenen Unterschied in der specifischen Drehung eine Verschiedenheit des Caseïns und Albuminats nicht ableiten lässt.

Von Höchstetter ${ }^{2}$ ) wurden in Hoppe's Laboratorium drei Bestimmungen der specifischen Drehung des Caseïns in einer Lösung von schwefelsaurer Magnesia gemacht, die nach der Methode von Denis dargestellt worden war, nämlich durch Eintragen krystallisirter schwefelsaurer Magnesia in die Milch, Waschen mit concentrirter Lösung dieses Salzes, Luösen in Wasser und Abfiltriren der Butter. Die drei Bestimmungen ergaben für geibes Licht ,als die specifische Drehung - $79^{\circ},-80^{\circ},-82^{\circ}$, also im Mittel etwa - $80^{\circ}$ "“

Könnte man anch zugeben, dass die von Höchstetter untersuchte Lösung in der That eine Lösung von reinem Caseïn in sohwefelsaurer Magnesia gewesen ist, so brauchen die Zahlen immerhin nicht die wirkliche speeifische Drehung des Caseïns anzugeben, insofern als ein Einfluss des Salzes auf das Drehungsvermögen des Caseïns, wenn auch nicht erwiesen, doch denkbar ist. Wenigstens ist eine solche Einwirkung vom Kochsalz bekannt. Hopp $\mathrm{e}^{\mathrm{s}}$ ) selbst hat gefunden, dass eine neatrale Serumeiweisslösung durch Sättigen mit Chlornatrium eine Stei-

1) Hoppe, Chem. Centr. 1865, 785 (Orig.M.).

2) Höcbstetter, Chem. Centr. 1865, 787.

J) Hoppe-Seyler, IIand. 1870, 199.

Journ. f. prakt, Chemie [2] Hd. 6 . 
50 Soxhlet: Beitrăge zur physiologischon Chemie

gerung der specifischen Drehung von $-56^{*}$ auf $-64^{\circ}$ für gelbes Licht erleidet. Vom Drehungsvermögen der Albuminate bestehen keine so genauen Angaben. HoppeSeyler ${ }^{1}$ ) hat nur ermittelt, dass eine schwach alkalische Lösung des Caseïns eine Linksdrelıung von $-\mathbf{7 6}^{\prime \prime}$, eine stark alkalische Lösung des Caseïns eine solehe von - 91" zeigt, und dass die Drehung des flüssigen Eieralbumins dureh Kalilauge bis auf $-\mathbf{4 7}^{\circ}$, die des geronnenen Eieralbumins auf $-58,5^{\circ}$, die des Serumalbumins auf $-86^{\circ}$ gesteigert werden konnte. Dazu kommt noch, dass, gleichfalls nach Hoppe-Seyler, bei längerer Einwirkung des Alkalis, besonders bei höherer Temperatur die Circumpolarisation wieder abnimmt.

Hieraus ist ersichtlieh, dass sich das Drehangsvermögen des Albuminats überhaupt noch nicht hat ermitteln lassen. Wollte man die vorliegenden Zahlen benützen, um aus ihnen einen Schluss auf die Identität oder Verschiedenheit der beiden in Rede stehenden Eiweisskörper abzuleiten, so könnte man ebenso gut, wie man hieraus ihre Verschiedenheit gefolgert hat, Beweise für ihre Identität aufzustellen versuchen. Beträgt die 'Drehung des Caseïns wirklich $-79^{\circ}$ bis $-82^{\circ}$, so käme sie der einer Kalialbuminatlösung von $-76^{\circ}$ oder $-86^{\circ}$ oder $-91^{\circ}$ nahe.

Die Bestimmung der specifischen Drehung eines Eiweisskörpers ist grossen Schwierigkeiten unterworfen, und $z$ war weit grösseren, als die einer anderen Substanz, weil in der quantitativen Bestimmung des in einer Lösung enthaltenen Eiweisskörpers wesentliche Fehlerquellen enthalten sind, abgesehen davon, dass die Methoden zur Trennung der Eiweisskörper, die stets in Gemengen auftreten äusserst unsichere sind. Man erinnere sich, dass die Eiweiskörper kaum vollständig aus ihren Lösungen gefällt werden, dass sie sich kaum vollständig von ihren Mineralbestandtheilen trennen lassen; man exinnere sich der Schwierigkeit einer vollkommenen Trocknung derselben, des Wägens mit dem Filter n. s. w. und man wird zugeben

1) Hoppe-Seyler, Chem. Centr. 1865, 787 and Handb., 207. 
müssen, dass auf die Angabe des Drehungsvermögens eines Eiweisskörpers kein zu grosses Gewicht gelegt werden darf. Bedenkt man ferner, dass das Drehungsvermögen einer Lösung abhängig ist davon, ob die Lösung frisch bereitet oder ob sie schon einige Zeit gestanden, von der Temperatur derselben u. s. w., Umstände, welche bei der Bestimmung der specifischen Drehung der. Eiweisskörper noch gar nicht genügend in Betracht gezogen worden sind, so gewinnen die Angaben über die specifische Drehung der Eiweisskörper auch nicht an Werth.

In Anbetracht aller dieser Verbältnisse wird man daher wohl der Ansicht sein müssen, dass sich aus der Verschiedenheit im Drehungsvermögen des Caseïns und des Albuminats eine Verschiedenheit der beiden Riweisskörper nicht ableiten lässt.

In den vorstehend beschriebenen Versuchen habe ich die Finwände erörtert, welche man gegen die Identität des Caseïns mit dem Kalialbuminat geltend gemacht hat, und von ihnen gezeigt, dass sie unhaltbar sind. Es wurde dargethan, dass das Caseïn sowohl als das Kalialbuminat aus alkalischer Lösung durch Lab gefüllt werden könne, dass die Filtration beider Eiweisskörper durch Thonzellen von denselben Umständen beeinflusst werde, dasa zwar dio Mileh, nicht aber das Caseïn, ebenso wenig wie das Albuminat durch kohlensaures Natron gefällt werde. Auch wurde gezeigt, dass beide Eiweisskörper von Alkalihydraten unter sonst gleichen Verhältnissen, unter Bildung von Schwefelalkali zersetzt werden, und dass sich auf die Cireumpolarisationsverschiedenheiten beider, so weit die Beobachtungen jetzt reichen: ein Untersehied der beiden Eiweisskörper nicht gründen lässt. Es stände somit der Annahme, dass die bekannten Figenschaften dieser beiden Eiweisssubstanzen dieselben seien, nichts entgegen und man wäre somit berechtigt, sie selbst für identisch zu erklären. In vielen anderen Fällen würde man auch kein Bedenken tragen, zwei einander so durchaus ähnliche Körper 
52 Soxhlet Beitrăge z. physiotog. Chemie der Milch.

für identisch zu halten; aber ein altes Vorurtheil wird ungern aufgegeben, und so kommt es, dass immer neue Einwände gemacht werden, deren Autoren Anderen die eingehende Prüfung und Beseitigung zuweisen. So hat sich in letzter Zieit wieder N. Lubavin ${ }^{1}$ ) gegen die Identität des Caseins und Albnminats ausgesprochen, weil dem Casein der Milch hartnäckig eine phosphorhaltige Substanz anhaftet die ex von diesem durch Lösungsmittel nicht trennen konnte, und geht sogar so weit, das Casein deshalb für eine chemische Verbindung eines Eiweisskörpers mit der phosphorhaltigen Substanz zu erklären. Es muss dahin gestellt bleiben, wie weit eine solche Behauptung berechtigt ist. Jedenfalls wird man aber annehmen dürfen, dass wenigstens der Eiweisskörper, welcher nach Lubavin mit der phosphorhaltigen Substanz verbunden ist, keinen Unterschied vom Kalialbuminat darbietet. Endgiultig wird sich die Frage von der Identität beider Eiweisskörper erst dann mit aller Bestimmtheit beantworten lassen, wenn man die chemische Constitution der Eiweisskörper überhaupt erforseht haben wird. - -

Vorliegende Untersuchungev wurden im hiesigen pathol.-chem. Universitäts-Laboratorium unter Leitung des Herrn Professor Huppert ausgeführt, welchem ich hier für seine Rathschläge und die vielseitige Anregung meinen Dank ausspreche.

Leipzig, Juni 1872.

1) N. Lubavin, in Hoppe-Seyler's med. chem. Untersuchungen. 4. Heft, 1871, 480 . 